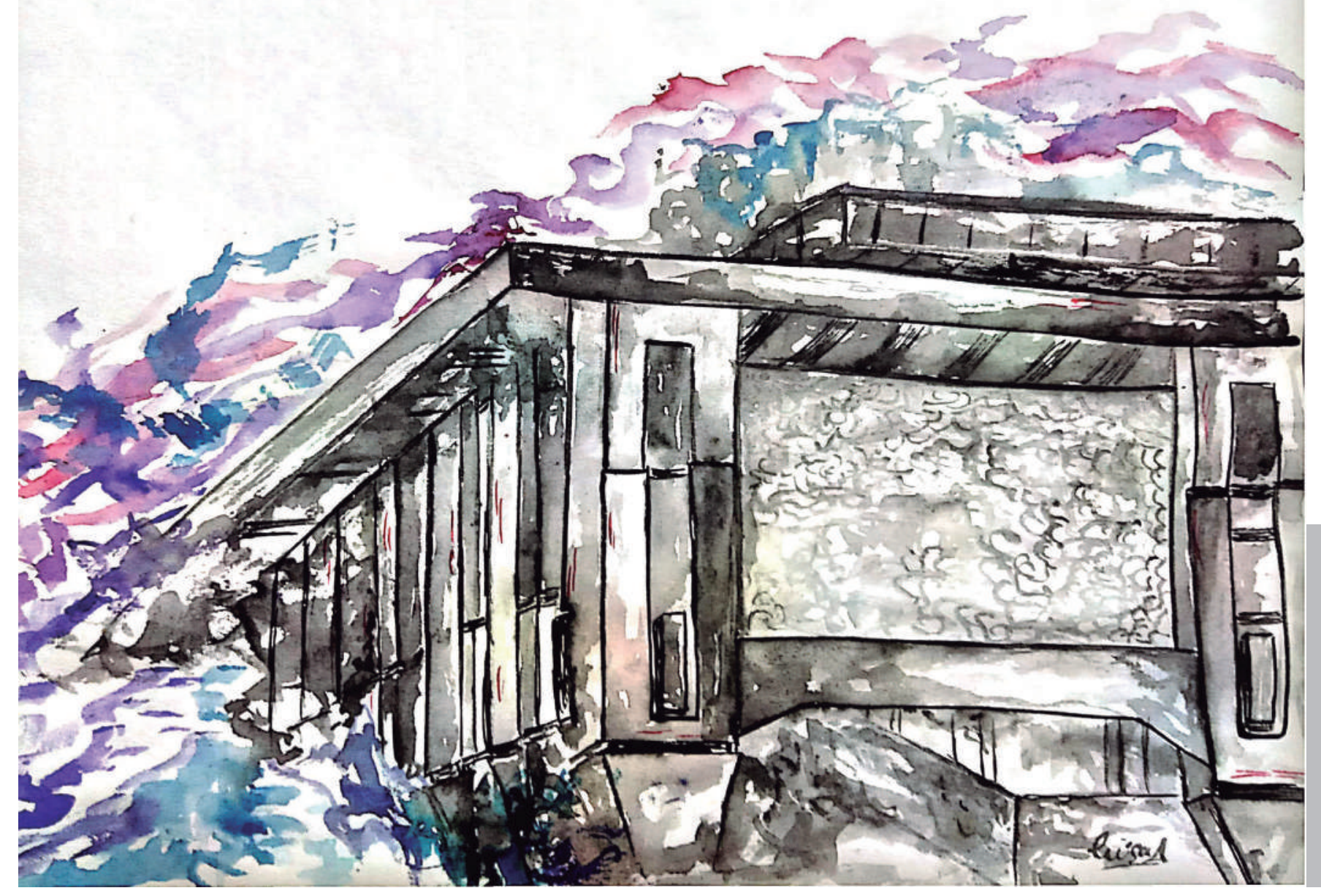

Sin título De la serie Memorias acuareladas Universidad de Antioquia Acuarela. $30 \times 25 \mathrm{~cm}$ 2019, Medellín 


\title{
Representaciones sobre la democracia, las instituciones y los actores gubernamentales en la Universidad de Antioquia*
}

\author{
Deicy Patricia Hurtado Galeano (Colombia)** \\ John Fredy Bedoya Marulanda (Colombia)*** \\ Xamara Mesa Betancur (Colombia) ${ }^{* * * *}$
}

\section{Resumen}

El artículo presenta una caracterización de la cultura política a partir de un análisis de correlaciones entre las imágenes y representaciones que tienen los universitarios sobre el sistema social, sus acciones en el ámbito político y la imagen que poseen del sistema político. Toma como caso la Universidad de Antioquia y ofrece una aproximación a las percepciones de la democracia y las instituciones políticas de representación, de control y de participación en ella. A partir de una encuesta a una muestra representativa de estudiantes, profesores y empleados administrativos se concluye que, si bien hay una amplia aceptación de la democracia como idea general en términos normativos, este presupuesto se debilita cuando se pasa del plano valorativo a su materialización, es decir, los universitarios realizan una evaluación crítica del funcionamiento de la democracia colombiana. Adicionalmente, se pudo inferir que en este universo político coexisten dos matrices o constelaciones de cultura política: una que valora los procedimientos y mecanismos democráticos y otra que se muestra proclive a prescindir de elementos sustanciales para el funcionamiento de una democracia.

\section{Palabras clave}

Comportamiento Político; Cultura Política; Instituciones Políticas; Sistema Político; Participación Política.

\footnotetext{
* Este artículo hace parte de la investigación Reconstrucción de universos políticos universitarios. Un estudio basado en el enfoque dimensional de la cultura política. Aprobado por el Comité para el Desarrollo de la Investigación (CODI), código 2012-04-43549838, en el marco de la línea de investigación Ciudadanía, culturas políticas y subjetividades del Grupo Estudios Políticos, Universidad de Antioquia.

${ }^{* *}$ Socióloga. Magíster en Filosofía Política. Grupo Estudios Políticos, Instituto de Estudios Políticos, Universidad de Antioquia UdeA. Calle 70 No. 52-21, Medellín, Colombia. Correo electrónico: deicy. hurtado@udea.edu.co - Orcid: https://orcid.org/0000-0001-5562-1267

*** Economista. Magíster en Ciencia Política. Grupo Estudios Políticos, Instituto de Estudios Políticos, Universidad de Antioquia UdeA. Calle 70 No. 52-21, Medellín, Colombia. Correo electrónico: john. bedoyam@udea.edu.co - Orcid: https://orcid.org/0000-0002-5616-4616

**** Politóloga. Magíster en Gobierno y Políticas Públicas. Grupo Estudios Políticos, Instituto de Estudios Políticos, Universidad de Antioquia UdeA. Calle 70 No. 52-21, Medellín, Colombia. Correo electrónico: xamara.mesa@udea.edu.co
} 


\title{
Cómo citar este artículo
}

Hurtado Galeano, Deicy Patricia; Bedoya Marulanda, John Fredy y Mesa Betancur, Xamara. (2019). Representaciones sobre la democracia, las instituciones y los actores gubernamentales en la Universidad de Antioquia. Estudios Políticos (Universidad de Antioquia), 55, pp. 246-281. http://doi.org/10.17533/udea.espo. n55a12

\section{Representations about Democracy, Institutions and Governmental Actors at the University of Antioquia}

\begin{abstract}
The article presents a characterization of the political culture from an analysis of correlations between images and representations that the students at the Universidad de Antioquia have on the social system, their actions in the political field and the image they have of the political system. The analysis offers an approximation to the perceptions of democracy and the political institutions of representation, control and participation in it. From a survey to a representative sample of students, professors and administrative employees, it is concluded that, while there is broad acceptance of democracy as a general idea in normative terms, this acceptance is weakened when university students not merely value democracy but undertake a critical evaluation of the way in which the Colombian democracy works. Moreover, it could be inferred that two matrices or constellations of political culture coexist in this political universe: one that values democratic procedures and mechanisms, and another one that is prone to dispense with substantial elements for the functioning of a democracy.
\end{abstract}

\section{Keywords}

Political Behavior; Political Culture; Political Institutions; Political System; Political Participation. 


\section{Introducción}

Los estudios sobre la cultura política tienen como espacio de indagación más frecuente los distintos ámbitos territoriales —nacional, departamental y local-, sin embargo, hay estudios de caso que pretenden analizar y comprender la configuración de la cultura política en determinados grupos poblacionales —mujeres, jóvenes, étnicos, entre otros-, así como en instituciones específicas como vía para construir líneas de base que permitan diseñar procesos formativos. Las instituciones de educación superior (IES), sobre todo las públicas, han sido uno de esos espacios institucionales que en América Latina se han examinado desde el punto de vista de la cultura política por distintas razones: a) son un reflejo de la composición socioeconómica de un país o una ciudad; b) son espacios políticos en los que convergen distintas corrientes ideológicas; c) en ellas están los ciudadanos con los mayores niveles educativos; d) los estudiantes constituyen el mayor porcentaje de su población y de ellos se dice que, en su mayoría, son apáticos frente a la política.

En América Latina, la literatura disponible muestra que es en México donde los estudios de cultura política en entornos universitarios han tenido mayor trayectoria, pero también en Brasil, Chile y Venezuela. En el caso de México han abordado asuntos como los procesos de socialización política de los estudiantes de universidades públicas y privadas (Crespo, 1988), la construcción de cultura política tras el paso de los estudiantes por la universidad (Álvarez y Camacho, 2009, 21-25 de septiembre), los niveles de legitimidad que los estudiantes universitarios le confieren a algunas de las instancias del sistema político, como los partidos políticos, la figura presidencial, la Policía, las votaciones (Piña, 2008), y la formación cívica de los estudiantes universitarios (Durand, 2002).

En Brasil se destacan los estudios referidos a los procesos de despolitización, desmovilización y apatía de los universitarios (Echegaray, 1990); en Chile han enfatizado también en las actitudes y orientaciones de desencanto hacia el sistema político chileno de un grupo creciente de universitarios que no se identifican con partidos o coaliciones partidistas (González et al., 2005); y en Venezuela se han abordado las prácticas discursivas y la construcción de representaciones de identidades políticas de los jóvenes universitarios (Bermúdez, Martínez y Sánchez, 2009). 
Representaciones sobre la democracia, las instituciones y los actores gubernamentales...

Por otro lado, es oportuno mencionar que los marcos metodológicos y los enfoques que han primado en estos procesos investigativos han estado relacionados con enfoques cualitativos de investigación social, particularmente, a partir de fundamentos epistemológicos como el hermenéutico, crítico e interpretativo; estrategias como la etnografía, la fenomenología, la teoría fundada, el estudio de caso y la investigación documental; y técnicas de recolección de información como los diarios de campo, la observación participante, las entrevistas, los grupos focales, las historias de vida, entre otros (Mendoza, Lorenzo, Flórez y Mendoza, 2011; Durand, 2002). Esta perspectiva metodológica — cualitativa - apela a la inclusión de ejercicios analíticos-comprensivos para el abordaje de narrativas de los participantes de las investigaciones, esto se da por medio de la interpretación discursiva, a través de la cual se organizan o esquematizan las percepciones y representaciones de los sujetos (Taguenca, 2013). Asimismo, se ha intentado incluir metodologías propias de la Ciencia Política para el estudio de la cultura política, es el caso de los análisis sistémicos para la interpretación de los componentes políticos por medio de una observación detallada y minuciosa de los fenómenos a estudiar (López, 2008).

Ahora bien, además del enfoque cualitativo, también se han desarrollado investigaciones tomando componentes o modelos cuantitativos, específicamente, por medio de encuestas de muestreo probabilístico que buscan un análisis descriptivo, exploratorio y multivariado (Mendoza et al., 2011), así como diseños no experimentales de tipo descriptivo y correlacionalcausal (Hernández, 2007).

En el caso colombiano, el análisis de la cultura política en ámbitos universitarios ha quedado subsumido en los estudios sobre juventud y política, con apartados específicos sobre los jóvenes universitarios y sus procesos de construcción de identidad y participación política (Vélez, Santamaría y Silva, 1984; Cubides, Laverde y Valderrama, 1998). Aunque también han despuntado algunas investigaciones relacionadas con la formación ciudadana y las expresiones organizativas de los jóvenes universitarios (Henao, Ocampo, Robledo y Lozano, 2008), así como sobre sus procesos de subjetividad política y los procesos organizativos (Díaz, Carmona y Salamanca, 2011). De acuerdo con esto, se puede inferir que los análisis sobre las imágenes, las representaciones y la confianza de los universitarios colombianos en el sistema político, en la democracia y en los gobernantes es una asignatura pendiente en nuestro contexto. 
En los aspectos metodológicos también han primado, al igual que en América Latina, los abordajes cualitativos por medio de estudios de caso y registros sobre experiencias juveniles y grupos focales (Zapata y Muñoz, 2013). Adicionalmente, se ha hecho una aproximación a métodos cuantitativos por medio de encuestas estandarizadas que permiten arrojar datos estadísticos y tendencias de variables a partir de una exploración de los documentos del Proyecto de Opinión Pública de América Latina (Lapop) o el Latinobarómetro (Jaramillo, 2012).

El objetivo de este artículo es caracterizar los significados y representaciones, así como las actitudes y comportamientos de los actores universitarios sobre la política. Qué saben, qué sienten, cómo juzgan la política y en qué acciones políticas se implican los sujetos. Para ello, se parte del contexto según el cual, pese a la dinámica de organización, participación y expresión política que ha caracterizado a la Universidad de Antioquia, no se dispone de estudios que permitan interpretarla y, menos aún, que contribuyan a caracterizar las culturas políticas de que es portadora la comunidad universitaria — profesores, estudiantes y empleados administrativos-, toda vez que la mayoría de los estudios realizados en el campo de la cultura política en la Universidad de Antioquia toman como objeto de análisis a los estudiantes y dejan por fuera a los demás estamentos que la conforman. En este sentido, se propone romper el imaginario común de que los jóvenes - los estudiantes - son los apáticos y desinteresados en la política, mientras que los adultos - los profesores y empleados — son portadores de una cultura política proclive a la participación y a la democracia, razón por la cual se hace la indagación en los tres estamentos que conforman la vida universitaria.

Adicionalmente, se plantea que en la Universidad de Antioquia coexisten distintas culturas políticas que están encarnadas en sus estudiantes, profesores y empleados no docentes, pero que no han sido suficientemente reconocidas, caracterizadas e interpretadas. Culturas políticas que se expresan en prácticas, acciones, discursos, motivaciones, sentidos, opiniones, percepciones, representaciones, entre otros elementos que configuran las formas como los sujetos universitarios piensan, sienten y actúan políticamente.

\section{Marco teórico}

Para abordar las anteriores pretensiones, esta investigación se fundamenta en el enfoque dimensional de la cultura política, la cual reconoce 
la validez del enfoque interpretativo, es decir, recupera el bagaje de las representaciones, símbolos e instituciones de una sociedad para establecer las bases o raíces de la cultura política, sin descuidar que dicho análisis debe ser complementado con estudios comparativos y estadísticos que expliquen las cotidianas percepciones y actitudes de la sociedad hacia la política, tal como lo ha propuesto el enfoque cuantitativo comparatista que hunde sus raíces, primero, en Gabriel Almond y Sidney Verba (1963; 1992), y luego en Ronald Inglehart (1988).

Por su parte, Leticia Heras (2002) propone construir una visión general e integradora de la forma como se interpreta y actúa en términos de lo político en una sociedad, y para ello reconoce el valioso aporte de María Luz Morán y Jorge Benedicto (1995) con su enfoque dimensional de la cultura política. Estos autores plantean que la comprensión de los fenómenos políticos, teniendo en cuenta las dimensiones sociales y culturales — los componentes no visibles de la política-, implica «[...] aprehender el modo en que interrelacionan y se afectan mutuamente, los valores, creencias, actitudes, lenguajes y discursos de las personas y grupos sociales en relación a lo público con los principales elementos constitutivos de los sistemas políticos y de la vida pública [...]» (Morán, 1999, p. 98). De manera que, para sociedades complejas como las contemporáneas, la cultura política es una vía para trazar el puente entre los marcos psicológicos, culturales y sociales de la acción política y los sistemas políticos realmente existentes.

Este enfoque integrador que se viene posicionando desde la década de 1990 reconoce la importancia de involucrar modelos cuantitativos que den cuenta de las principales dimensiones de la cultura política y de las orientaciones hacia el sistema político, estudiando tendencias en grandes conjuntos poblacionales. Modelos analíticos cuantitativos que acopian sistemáticamente distintas bases de datos sobre la opinión —actitudes, valores y comportamientos - de los ciudadanos sobre el sistema social y político, el Gobierno, las elecciones, los Parlamentos o Congresos; también indagan por la asociatividad y la implicación política de los ciudadanos, la confianza en las instituciones, entre otras dimensiones. El Estudio Mundial de Valores y los barómetros de distintas latitudes — Latinoamérica, África, Asia, Europaconstituyen algunas de los más importantes diseños metodológicos y bases de datos que incluyen dimensiones y variables fundamentales para el análisis de la cultura política. 
Y en ese sentido, el modelo dimensional de la cultura política recoge de los modelos cuantitativos la necesidad de establecer indicadores que «permitan analizar empíricamente las pautas culturales con que los ciudadanos enfrentan el ámbito político y la estructura de relaciones que las vincula entre sí en un todo más o menos coherente» (Morán y Benedicto, 1995, p. 29). Parte, entonces, del reconocimiento de que el eje básico que organiza las distintas dimensiones de la cultura política es el de la relación ciudadanosistema político, lo que implica, en primer lugar, concebir «el individuo como ciudadano-actor de una determinada politeya»; y en segundo lugar, «el sistema político en tanto organización específica dentro de una comunidad que recibe y procesa las demandas de los distintos actores y produce una serie de resultados en forma de acciones políticas institucionales» (Morán y Benedicto, 1995, p. 31).

En este enfoque se otorga importancia a asuntos como: la adquisición de información política, los hábitos asociativos y las evaluaciones que los ciudadanos hacen del sistema político. Esta última dimensión, que alude a las bases de legitimidad del sistema político, incluye: las imágenes de los ciudadanos sobre el sistema político y su capacidad de representación, así como los juicios de los ciudadanos sobre los productos resultantes de la actividad institucional del sistema. Las tres dimensiones básicas propuestas para conocer los rasgos fundamentales de la cultura política de una sociedad son: las imágenes y representaciones — creencias y valores— que los individuos tienen respecto al sistema social en el que viven; las acciones específicas que llevan a cabo los ciudadanos, esto es, las implicaciones personales con las cuestiones políticas; y las imágenes del sistema político.

\section{Metodología}

Este artículo enfatiza en las siguientes dimensiones: a) las percepciones sobre la democracia, el régimen democrático y las actitudes democráticas de los sujetos; y b) la confianza en las instituciones políticas y en los gobernantes. Además de indagar por el sistema social y político general, el instrumento aplicado indaga por la percepción de los universitarios sobre el gobierno, las instituciones y la democracia universitaria.

El principal instrumento de recolección de información fue la encuesta realizada para la investigación Reconstrucción de universos políticos 
universitarios. Un estudio basado en el enfoque dimensional de la cultura política, en la que se aplicaron 1024 cuestionarios cara a cara en la Universidad de Antioquia entre abril y junio de 2015, distribuidos de la siguiente manera: 632 estudiantes de pregrado y posgrado; 244 profesores vinculados, ocasionales y de cátedra; y 148 empleados administrativos de carrera, de libre nombramiento y remoción, de contrato de servicios y provisionales. Se usó un muestreo aleatorio simple, estratificado por las proporciones de la población según estamento y áreas del conocimiento, con una confiabilidad de $95 \%$ y un margen de error de $3 \%$.

Con la necesidad de reducir la dimensionalidad de la información recolectada, se hizo uso de un análisis de componentes principales categóricos, una técnica estadística de síntesis de la información o reducción de la dimensión —número de variables—, es decir, ante un banco de datos con muchas variables, el objetivo es reducirlas a un menor número, perdiendo la menor cantidad de información posible (Castaño y Moreno, 1994). Este método permite observar la relación de los factores con las variables iniciales — se debe estudiar tanto el signo como la magnitud de las correlaciones—, y para este artículo se trata de encontrar la relación entre las diferentes variables que dan cuenta de las dimensiones de la cultura política para crear perfiles sobre la misma, lo que permite hallar las correlaciones existentes entre las variables incluidas en el estudio. De este modo, el proceso metodológico comienza por explicar estas correlaciones, a la vez que se realizan los análisis descriptivos de acuerdo con los estamentos universitarios para dar razón de la coexistencia de diversas culturas políticas en el claustro.

\section{Las dimensiones de la cultura política en la Universidad de Antioquia}

La multidimensionalidad de la cultura política invita a analizar el fenómeno de manera descriptiva, tratando de identificar la complejidad de la interrelación de las dimensiones que la componen: a) las imágenes y representaciones de los ciudadanos sobre el sistema social, b) sus acciones en el ámbito político y c) la imagen que poseen del sistema político. Todas analizadas con una mirada descriptiva más que explicativa o comprensiva, es decir, sin la presencia de variables independientes. Los resultados de este ejercicio agruparon las variables en las tres dimensiones enunciadas ${ }^{1}$

${ }^{1}$ La varianza total explicada por los tres componentes es de 37,5\% y a partir de este componente los demás explican menos de $1 \%$. 
que muestran las particularidades del caso estudiado. Lo importante es señalar que la lectura de la correlación entre las dimensiones y las variables medidas permiten entender los universos políticos de la Universidad de Antioquia, en primer lugar, mediante las expectativas que existen alrededor de la democracia; en segundo lugar, las representaciones del sistema político y social expresado en el nivel de confianza en instituciones del Estado y actores sociales; y en tercer lugar, el papel de la participación ciudadana y del Estado en el ordenamiento social y político.

De esta manera, como se muestra en la tabla 1, en la primera dimensión se correlacionan positivamente todas aquellas variables que dan cuenta de las expectativas que los encuestados tienen frente a la democracia y los elementos que la componen. De aquí se desprenden dos observaciones: la primera, que sus elementos constitutivos, según los encuestados, abarcan mucho más que el simple acto de elegir a los gobernantes; por el contrario, se aceptan los múltiples componentes que esta posee como forma de ordenamiento social, ya que encierra, entre otras cosas, derechos económicos, individuales y colectivos como el acceso al empleo y el progreso, derechos políticos como el respeto por los derechos humanos, la libertad de asociación política, las garantías de la oposición, la participación ciudadana activa y, finalmente, otras que dan cuenta de un ordenamiento gubernamental descentralizado.

La segunda observación alude a que este componente reúne otras dos variablesque se correlacionan de manera negativa y dan cuenta de la percepción que poseen los encuestados sobre las posibilidades de comunicación política en su contexto próximo. En cierto sentido, esto puede leerse como un matiz a las expectativas que se forman alrededor de la democracia, cuyo funcionamiento depende de estos procesos de comunicación. ${ }^{2}$ Sin embargo, se debe ver con cuidado este resultado ya que dicha correlación es muy baja en comparación con las otras variables que incluye el factor.

En esta dimensión, las diferencias entre los estamentos universitarios no son muy notorias. Como se resume en la tabla 2, se evidencia que al menos la mitad de profesores, estudiantes y empleados tienen grandes exigencias sobre los elementos constitutivos de la democracia, con pequeñas diferencias estadísticas — según el chi-cuadrado <0,05—: en la percepción

\footnotetext{
${ }^{2}$ ¿En la universidad las personas se reúnen para hablar de política?, y ¿en la universidad las personas son capaces de escuchar a otras con ideas distintas a las suyas?
} 
Representaciones sobre la democracia, las instituciones y los actores gubernamentales...

sobre la existencia de mecanismos para que los ciudadanos participen, el derecho a que las minorías participen, la existencia del Congreso, la elección de las autoridades locales, la elección periódica de gobernantes, el equilibrio de poderes y la prensa libre; todas estas valoradas en mayor medida por profesores.

Tabla 1. Aspectos que no se pueden descartar en una democracia.

\begin{tabular}{|c|c|}
\hline Variable & $\begin{array}{l}\text { Correlación con el } \\
\text { primer componente }\end{array}$ \\
\hline Desarrollo-progreso-crecimiento económico & 0,890 \\
\hline Respeto por los derechos humanos & 0,886 \\
\hline Mayores oportunidades de empleo & 0,882 \\
\hline Educación política & 0,876 \\
\hline Justicia y equidad & 0,867 \\
\hline Libertad de asociación política & 0,863 \\
\hline Igualdad de oportunidades & 0,858 \\
\hline Garantías a la oposición política & 0,852 \\
\hline $\begin{array}{l}\text { Mecanismos para que los ciudadanos participen en la gestión } \\
\text { pública }\end{array}$ & 0,842 \\
\hline $\begin{array}{l}\text { Autoridades locales, municipales y departamentales elegidas por } \\
\text { voto popular }\end{array}$ & 0,841 \\
\hline Jueces, juzgados, tribunales, cortes & 0,834 \\
\hline Familias e instituciones educativas democráticas & 0,827 \\
\hline $\begin{array}{l}\text { Equilibrio entre los poderes Ejecutivo, Legislativo y Judicial, y los } \\
\text { órganos de control y electorales }\end{array}$ & 0,823 \\
\hline $\begin{array}{l}\text { Que las personas puedan cambiar las leyes por medio de un } \\
\text { referendo }\end{array}$ & 0,818 \\
\hline Elecciones periódicas y libres de los gobernantes & 0,803 \\
\hline Congreso & 0,775 \\
\hline El respeto por los derechos de las minorías sociales & 0,761 \\
\hline Prensa libre & 0,725 \\
\hline Respeto por la autonomía de los municipios y departamentos & 0,841 \\
\hline
\end{tabular}

Fuente: elaboración propia. 
Tabla 2. Aspectos que no se pueden descartar en una democracia. Porcentaje por estamentos.

\begin{tabular}{|c|c|c|c|c|}
\hline Estamentos & Profesor & Estudiante & Empleado & Total \\
\hline Prensa libre & 51,70 & 38,50 & 45,30 & 42,60 \\
\hline $\begin{array}{l}\text { El respeto por los derechos de las minorías } \\
\text { sociales }\end{array}$ & 50,40 & 44,70 & 38,50 & 45,20 \\
\hline Jueces, juzgados, tribunales, cortes & 49,20 & 45,80 & 40,50 & 45,80 \\
\hline Congreso & 49,60 & 47,10 & 37,20 & 46,20 \\
\hline $\begin{array}{l}\text { Elecciones periódicas y libres de los } \\
\text { gobernantes }\end{array}$ & 52,10 & 47,10 & 40,50 & 47,30 \\
\hline $\begin{array}{l}\text { Equilibrio entre los poderes Ejecutivo, } \\
\text { Legislativo y Judicial, y los órganos de } \\
\text { control y electorales }\end{array}$ & 53,70 & 45,50 & 47,30 & 47,70 \\
\hline Garantías a la oposición política & 51,70 & 47,10 & 45,90 & 48,00 \\
\hline Libertad de asociación política & 51,20 & 48,60 & 43,90 & 48,50 \\
\hline Desarrollo-progreso-crecimiento económico & 52,10 & 46,90 & 50,70 & 48,70 \\
\hline Mayores oportunidades de empleo & 53,70 & 48,30 & 50,00 & 49,90 \\
\hline $\begin{array}{l}\text { Familias e instituciones educativas } \\
\text { democráticas }\end{array}$ & 53,70 & 50,60 & 52,70 & 51,60 \\
\hline Educación política & 56,20 & 50,30 & 50,70 & 51,80 \\
\hline Respeto por los derechos humanos & 52,10 & 52,60 & 49,30 & 52,00 \\
\hline $\begin{array}{l}\text { Autoridades locales, municipales y } \\
\text { departamentales elegidas por voto popular }\end{array}$ & 59,90 & 49,30 & 52,00 & 52,20 \\
\hline Igualdad de oportunidades & 56,20 & 53,60 & 49,30 & 53,60 \\
\hline $\begin{array}{l}\text { Respeto por la autonomía de los municipios } \\
\text { y departamentos }\end{array}$ & 60,70 & 51,70 & 51,40 & 53,80 \\
\hline $\begin{array}{l}\text { Que las personas puedan cambiar las leyes } \\
\text { por medio de un referendo }\end{array}$ & 55,80 & 53,50 & 52,70 & 53,90 \\
\hline Justicia y equidad & 59,10 & 52,60 & 53,40 & 54,30 \\
\hline $\begin{array}{l}\text { Mecanismos para que los ciudadanos } \\
\text { participen en la gestión pública }\end{array}$ & 62,80 & 53,70 & 54,70 & 56,00 \\
\hline
\end{tabular}

Fuente: elaboración propia. 
Representaciones sobre la democracia, las instituciones y los actores gubernamentales...

Sin embargo, no se puede dejar de lado que las visiones antes expuestas conviven con la otra mitad de miembros de la comunidad universitaria que parecen ser más radicales en relación con cuáles son los componentes que pueden descartarse de una democracia (véase el total en la tabla 2): la prensa libre, el respeto por los derechos de las minorías, los jueces, el Congreso, las elecciones, el equilibrio de poderes, las garantías de la oposición política, la libertad de asociación política, el desarrollo económico y las oportunidades de empleo; elementos que son menos valorados por estudiantes y empleados.

La segunda dimensión de la cultura política relaciona tres grupos de variables: el primero hace referencia a la confianza que sienten los entrevistados en relación con diferentes instituciones del Estado, así como las instituciones del gobierno universitario y actores del claustro. El segundo grupo de variables son las percepciones sobre el nivel de involucramiento de los actores universitarios en los problemas de la universidad. Finalmente, el último grupo residual — con muy baja correlación — da cuenta de múltiples factores en el marco de la evaluación a las acciones de los universitarios (véase tabla 3).

Tabla 3. Confianza en instituciones políticas o actores sociales.

\begin{tabular}{|l|c|}
\hline \multicolumn{1}{|c|}{ Variable } & $\begin{array}{c}\text { Correlación } \\
\text { con el segundo } \\
\text { componente }\end{array}$ \\
\hline Concejos municipales y distritales & 0,702 \\
\hline Contralorías (nacional, departamental y municipal) & 0,688 \\
\hline Asamblea departamental & 0,687 \\
\hline Jueces y magistrados & 0,636 \\
\hline Defensoría del Pueblo & 0,622 \\
\hline Alcaldía Municipal & 0,616 \\
\hline Fiscalía General de la Nación & 0,616 \\
\hline Congreso de la República & 0,607 \\
\hline Procuraduría General de la Nación & 0,606 \\
\hline Gobernación & 0,604 \\
\hline Presidencia de la República & 0,603 \\
\hline
\end{tabular}


Deicy Hurtado Galeano, John Fredy Bedoya, Xamara Mesa

Tabla 3. (Continuación)

\begin{tabular}{|c|c|}
\hline Fuerzas Militares (Ejército y Fuerza Aérea) & 0,602 \\
\hline Registraduría Nacional del Estado Civil & 0,598 \\
\hline Policía & 0,567 \\
\hline Partidos o movimientos políticos & 0,563 \\
\hline Organizaciones no gubernamentales (ONG) & 0,551 \\
\hline Empresarios & 0,531 \\
\hline Sindicatos & 0,488 \\
\hline Sistema educativo & 0,488 \\
\hline Medios de comunicación & 0,479 \\
\hline Iglesias, organizaciones o grupos religiosos & 0,442 \\
\hline Vicerrectores & 0,438 \\
\hline Organizaciones de jubilados & 0,412 \\
\hline Empleados administrativos de la universidad & 0,408 \\
\hline Miembros del Consejo Académico & 0,404 \\
\hline Rector de la Universidad & 0,401 \\
\hline Organizaciones y colectivos estudiantiles & 0,401 \\
\hline Miembros del Consejo Superior Universitario & 0,396 \\
\hline Organizaciones de empleados no docentes & 0,394 \\
\hline Investigadores & 0,344 \\
\hline Consejo Superior Universitario & 0,337 \\
\hline Consejo Académico & 0,335 \\
\hline Universidades & 0,332 \\
\hline Decanos & 0,321 \\
\hline Profesores & 0,315 \\
\hline Empleados administrativos & 0,305 \\
\hline Vigilantes de la universidad & 0,304 \\
\hline Las personas respetan los derechos de los demás en Colombia & 0,303 \\
\hline $\begin{array}{l}\text { Compromiso del Rector en la solución de los problemas de la } \\
\text { Universidad }\end{array}$ & 0,282 \\
\hline
\end{tabular}


Representaciones sobre la democracia, las instituciones y los actores gubernamentales...

Tabla 3. (Continuación)

\begin{tabular}{|l|c|}
\hline $\begin{array}{l}\text { Compromiso de los jefes de Departamentos, Escuelas e Institutos en } \\
\text { la solución de los problemas de la Universidad }\end{array}$ & 0,270 \\
\hline $\begin{array}{l}\text { Compromiso de otros empleados en la solución de los problemas } \\
\text { de la Universidad }\end{array}$ & 0,259 \\
\hline Confianza en los compañeros de trabajo o estudio & 0,252 \\
\hline Satisfacción con el funcionamiento de la democracia colombiana & 0,252 \\
\hline Las personas respetan la ley en Colombia & 0,239 \\
\hline $\begin{array}{l}\text { Compromiso de los profesores-investigadores en la solución de los } \\
\text { problemas de la Universidad }\end{array}$ & 0,238 \\
\hline Las personas respetan los derechos de los demás en la Universidad & 0,235 \\
\hline Igual trato a hombres y mujeres en la Universidad & 0,228 \\
\hline $\begin{array}{l}\text { Necesidad de los partidos políticos para el funcionamiento de la } \\
\text { democracia }\end{array}$ & 0,228 \\
\hline Las personas respetan la ley en la Universidad & 0,209 \\
\hline $\begin{array}{l}\text { ¿La situación económica actual del país es mejor, igual o peor que } \\
\text { hace un año? }\end{array}$ & 0,190 \\
\hline
\end{tabular}

Fuente: elaboración propia.

Dado lo anterior, este componente cobra importancia si se entienda que, junto con las expectativas hacia la democracia (primer componente), otra dimensión importante de la cultura política es la confianza y la percepción que se posee sobre las instituciones y el nivel de empoderamiento de los actores, dos dimensiones que están fuertemente ligadas a este segundo componente. Esto evidencia una intensa interacción entre las imágenes y representaciones de los ciudadanos sobre el sistema político y el gobierno universitario, así como de las acciones de los actores en su contexto próximo.

Esta dimensión que involucra las instituciones políticas y los actores sociales a través de la confianza y las percepciones sobre el nivel de involucramiento dan una lectura poco optimista. En relación con la confianza que se posee hacia las instituciones del Estado, en ninguno de los estamentos se expresa mayoritariamente confiar en ellos; sin embargo, se 
debe anotar que las Alcaldías municipales, las fuerzas militares, los grupos religiosos, las Defensorías del Pueblo, las ONG, las Gobernaciones, la Universidad como institución, la Fiscalía, la Registraduría, la Contraloría, los Concejos municipales, los sindicatos y los empresarios son los que salen mejor librados, en comparación con otras instituciones nacionales de representación y elección. Por estamentos, los niveles de confianza no son muy variables, aunque estos son un tanto mayores entre los empleados (véase tabla 4).

Tabla 4. Confianza en instituciones políticas o actores sociales. Porcentaje por estamentos.

\begin{tabular}{|c|c|c|c|c|c|}
\hline \multirow{2}{*}{\multicolumn{2}{|c|}{ Variable }} & \multicolumn{4}{|c|}{ Vinculación con la Universidad } \\
\hline & & \multirow{2}{*}{\begin{tabular}{c|} 
Profesor \\
5 \\
\end{tabular}} & \multirow{2}{*}{$\frac{\text { Estudiante }}{3}$} & \multirow{2}{*}{$\frac{\text { Empleado }}{7}$} & \multirow{2}{*}{$\frac{\text { Total }}{4}$} \\
\hline Procuraduría General de la & Muy confiables & & & & \\
\hline Nación & Algo confiables & 24 & 25 & 26 & 25 \\
\hline & Poco confiables & 41 & 42 & 31 & 40 \\
\hline & Nada confiables & 21 & 20 & 13 & 20 \\
\hline & No los conoce & 8 & 10 & 22 & 11 \\
\hline \multirow[t]{5}{*}{ Alcaldía Municipal } & Muy confiables & 6 & 4 & 7 & 5 \\
\hline & Algo confiables & 34 & 32 & 34 & 32 \\
\hline & Poco confiables & 42 & 44 & 41 & 43 \\
\hline & Nada confiables & 15 & 18 & 14 & 17 \\
\hline & No los conoce & 3 & 3 & 4 & 3 \\
\hline \multirow{5}{*}{$\begin{array}{l}\text { Fuerzas militares (Ejército y } \\
\text { Fuerza Aérea) }\end{array}$} & Muy confiables & 5 & 4 & 3 & 4 \\
\hline & Algo confiables & 30 & 28 & 32 & 29 \\
\hline & Poco confiables & 38 & 39 & 36 & 38 \\
\hline & Nada confiables & 23 & 26 & 21 & 25 \\
\hline & No los conoce & 3 & 3 & 8 & 4 \\
\hline \multirow{5}{*}{$\begin{array}{l}\text { Iglesias, organizaciones o } \\
\text { grupos religiosos }\end{array}$} & Muy confiables & 4 & 4 & 3 & 4 \\
\hline & Algo confiables & 38 & 29 & 36 & 32 \\
\hline & Poco confiables & 30 & 38 & 34 & 35 \\
\hline & Nada confiables & 28 & 26 & 22 & 26 \\
\hline & No los conoce & 1 & 3 & 5 & 3 \\
\hline
\end{tabular}


Representaciones sobre la democracia, las instituciones y los actores gubernamentales...

Tabla 4. (Continuación)

\begin{tabular}{|c|c|c|c|c|c|}
\hline \multirow[t]{5}{*}{ Congreso de la República } & Muy confiables & 1 & 0 & 1 & 1 \\
\hline & Algo confiables & 15 & 17 & 13 & 16 \\
\hline & Poco confiables & 43 & 38 & 38 & 39 \\
\hline & Nada confiables & 36 & 38 & 32 & 36 \\
\hline & No los conoce & 5 & 7 & 16 & 8 \\
\hline \multirow[t]{5}{*}{ Jueces y magistrados } & Muy confiables & 3 & 1 & 1 & 2 \\
\hline & Algo confiables & 24 & 20 & 16 & 21 \\
\hline & Poco confiables & 38 & 42 & 42 & 41 \\
\hline & Nada confiables & 29 & 30 & 20 & 28 \\
\hline & No los conoce & 6 & 7 & 21 & 8 \\
\hline \multirow[t]{5}{*}{ Asamblea Departamental } & Muy confiables & 2 & 2 & 2 & 2 \\
\hline & Algo confiables & 21 & 24 & 19 & 22 \\
\hline & Poco confiables & 40 & 39 & 31 & 38 \\
\hline & Nada confiables & 25 & 20 & 21 & 21 \\
\hline & No los conoce & 11 & 15 & 27 & 16 \\
\hline \multirow{5}{*}{$\begin{array}{l}\text { Organizaciones no } \\
\text { gubernamentales (ONG) }\end{array}$} & Muy confiables & 6 & 4 & 3 & 4 \\
\hline & Algo confiables & 42 & 41 & 29 & 39 \\
\hline & Poco confiables & 25 & 33 & 33 & 31 \\
\hline & Nada confiables & 18 & 11 & 10 & 12 \\
\hline & No los conoce & 10 & 11 & 27 & 13 \\
\hline \multirow{5}{*}{$\begin{array}{l}\text { Contralorías (nacional, } \\
\text { departamental y municipal) }\end{array}$} & Muy confiables & 3 & 2 & 4 & 3 \\
\hline & Algo confiables & 26 & 32 & 24 & 29 \\
\hline & Poco confiables & 40 & 36 & 34 & 37 \\
\hline & Nada confiables & 20 & 14 & 13 & 15 \\
\hline & No los conoce & 11 & 16 & 24 & 16 \\
\hline \multirow{5}{*}{$\begin{array}{l}\text { Concejos municipales y } \\
\text { distritales }\end{array}$} & Muy confiables & 3 & 2 & 3 & 2 \\
\hline & Algo confiables & 20 & 25 & 17 & 23 \\
\hline & Poco confiables & 43 & 40 & 30 & 39 \\
\hline & Nada confiables & 20 & 17 & 18 & 18 \\
\hline & No los conoce & 15 & 16 & 32 & 18 \\
\hline \multirow[t]{5}{*}{ Sindicatos } & Muy confiables & 4 & 2 & 1 & 2 \\
\hline & Algo confiables & 31 & 40 & 26 & 36 \\
\hline & Poco confiables & 50 & 41 & 55 & 45 \\
\hline & Nada confiables & 12 & 10 & 12 & 11 \\
\hline & No los conoce & 3 & 8 & 6 & 6 \\
\hline
\end{tabular}


Tabla 4. (Continuación)

\begin{tabular}{|c|c|c|c|c|c|}
\hline \multirow[t]{5}{*}{ Policía } & Muy confiables & 2 & 1 & 3 & 2 \\
\hline & Algo confiables & 27 & 24 & 18 & 24 \\
\hline & Poco confiables & 50 & 40 & 47 & 43 \\
\hline & Nada confiables & 20 & 35 & 31 & 31 \\
\hline & No los conoce & 1 & 0 & 1 & 1 \\
\hline \multirow[t]{5}{*}{ Medios de comunicación } & Muy confiables & 1 & 1 & 2 & 1 \\
\hline & Algo confiables & 33 & 22 & 34 & 26 \\
\hline & Poco confiables & 38 & 41 & 45 & 41 \\
\hline & Nada confiables & 28 & 35 & 18 & 31 \\
\hline & No los conoce & 0 & 1 & 1 & 0 \\
\hline \multirow{5}{*}{$\begin{array}{l}\text { Partidos o movimientos } \\
\text { políticos }\end{array}$} & Muy confiables & 1 & 1 & 1 & 1 \\
\hline & Algo confiables & 12 & 18 & 8 & 15 \\
\hline & Poco confiables & 46 & 43 & 44 & 44 \\
\hline & Nada confiables & 37 & 34 & 35 & 35 \\
\hline & No los conoce & 4 & 4 & 12 & 5 \\
\hline \multirow[t]{5}{*}{ Defensoría del Pueblo } & Muy confiables & 6 & 4 & 3 & 4 \\
\hline & Algo confiables & 37 & 41 & 35 & 39 \\
\hline & Poco confiables & 38 & 35 & 29 & 35 \\
\hline & Nada confiables & 16 & 13 & 19 & 15 \\
\hline & No los conoce & 4 & 7 & 14 & 7 \\
\hline \multirow[t]{5}{*}{ Gobernación } & Muy confiables & 6 & 3 & 3 & 4 \\
\hline & Algo confiables & 47 & 37 & 45 & 40 \\
\hline & Poco confiables & 30 & 40 & 37 & 38 \\
\hline & Nada confiables & 15 & 16 & 13 & 15 \\
\hline & No los conoce & 2 & 4 & 2 & 3 \\
\hline \multirow[t]{5}{*}{ Universidades } & Muy confiables & 16 & 15 & 10 & 14 \\
\hline & Algo confiables & 59 & 60 & 65 & 60 \\
\hline & Poco confiables & 16 & 23 & 16 & 20 \\
\hline & Nada confiables & 8 & 3 & 6 & 5 \\
\hline & No los conoce & 0 & 0 & 3 & 1 \\
\hline \multirow[t]{5}{*}{ Fiscalía General de la Nación } & Muy confiables & 5 & 3 & 1 & 3 \\
\hline & Algo confiables & 29 & 32 & 22 & 30 \\
\hline & Poco confiables & 45 & 41 & 46 & 43 \\
\hline & Nada confiables & 18 & 18 & 13 & 17 \\
\hline & No los conoce & 4 & 6 & 18 & 7 \\
\hline
\end{tabular}


Representaciones sobre la democracia, las instituciones y los actores gubernamentales...

Tabla 4. (Continuación)

\begin{tabular}{|l|l|c|c|c|c|}
\hline \multirow{4}{*}{$\begin{array}{l}\text { Registraduría Nacional del } \\
\text { Estado Civil }\end{array}$} & Muy confiables & 9 & 8 & 6 & 8 \\
\cline { 2 - 6 } & Algo confiables & 35 & 36 & 21 & 34 \\
\cline { 2 - 6 } & Poco confiables & 41 & 40 & 44 & 41 \\
\cline { 2 - 6 } & Nada confiables & 12 & 11 & 14 & 12 \\
\cline { 2 - 6 } & No los conoce & 2 & 5 & 14 & 6 \\
\hline Presidencia de la República & Muy confiables & 3 & 1 & 2 & 1 \\
\cline { 2 - 6 } & Algo confiables & 20 & 21 & 22 & 21 \\
\cline { 2 - 6 } & Poco confiables & 46 & 44 & 44 & 44 \\
\cline { 2 - 6 } & Nada confiables & 30 & 33 & 25 & 31 \\
\cline { 2 - 6 } & No los conoce & 1 & 1 & 7 & 2 \\
\hline Sistema educativo & Muy confiables & 5 & 3 & 3 & 4 \\
\cline { 2 - 6 } & Algo confiables & 49 & 42 & 50 & 45 \\
\cline { 2 - 6 } & Poco confiables & 35 & 36 & 35 & 36 \\
\cline { 2 - 6 } & Nada confiables & 12 & 18 & 10 & 16 \\
\hline & No los conoce & 0 & 0 & 1 & 0 \\
\hline \multirow{5}{*}{ Empresarios } & Muy confiables & 2 & 1 & 4 & 2 \\
\hline & Algo confiables & 36 & 34 & 27 & 33 \\
\hline & Poco confiables & 44 & 42 & 52 & 44 \\
\hline & Nada confiables & 16 & 18 & 12 & 17 \\
\hline & No los conoce & 2 & 5 & 5 & 4 \\
\hline
\end{tabular}

Fuente: elaboración propia.

En contraste con lo anterior, los actores universitarios, incluso aquellos que representan los órganos de gobierno, son mejor valorados en términos de confianza. En general, esto denota un mayor apego a estos grupos representativos de los estamentos y sus actores en relación con las instancias externas a la Universidad. Aquí también debe señalarse la mayor variabilidad en las opiniones por estamentos, por ejemplo, los empleados confían menos en los colectivos de estudiantes, de empleados no docentes y jubilados, y en los actores que componen los otros estamentos. Mientras que los estudiantes muestran mayores niveles de desconfianza hacia los actores que representan el Gobierno universitario como el Rector, el Consejo Académico, el Consejo Superior, los vicerrectores y los empleados administrativos (véase tabla 5). 
Tabla 5. Confianza en actores universitarios. Porcentaje por estamentos.

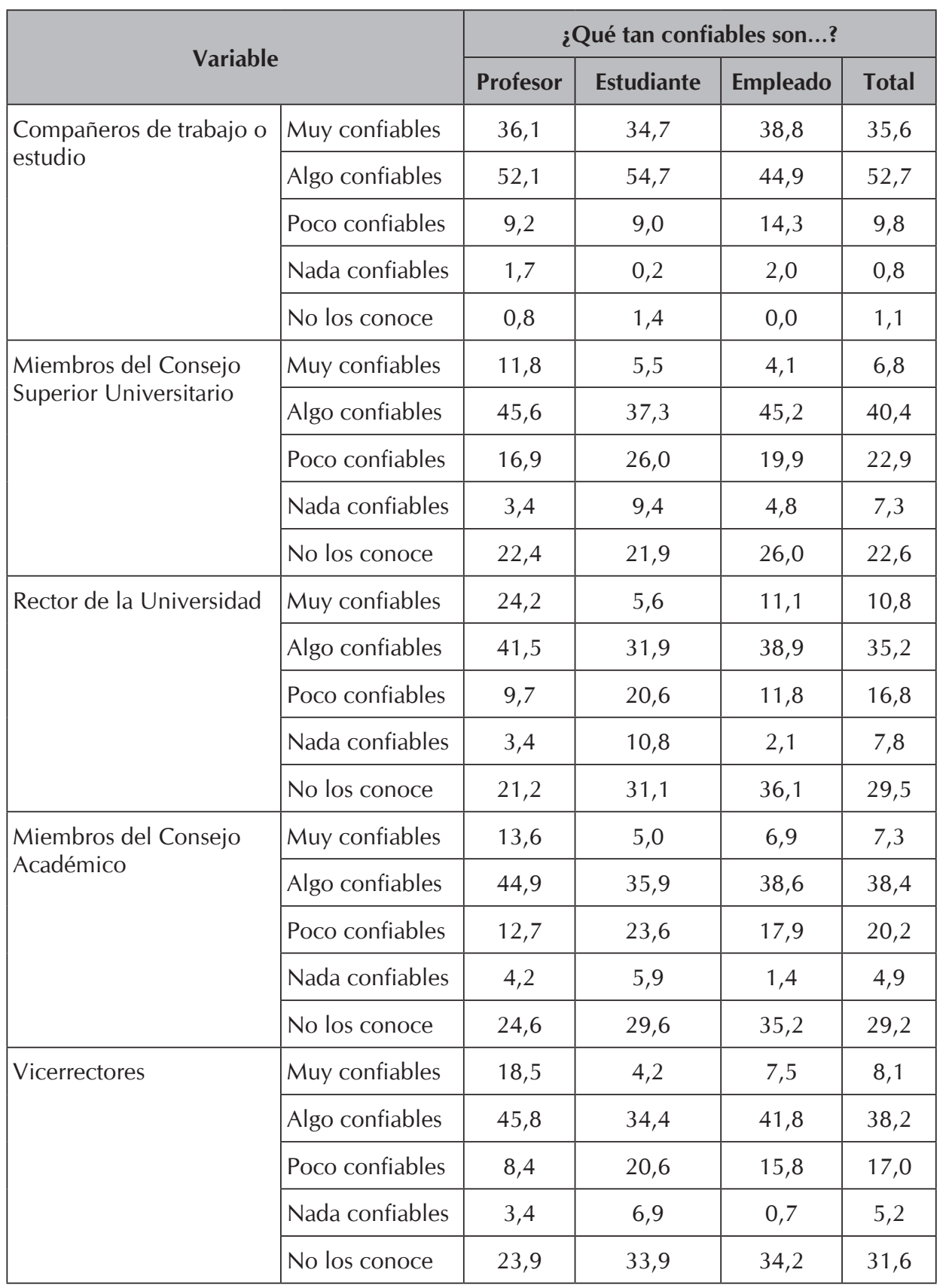


Representaciones sobre la democracia, las instituciones y los actores gubernamentales...

Tabla 5. (Continuación)

\begin{tabular}{|c|c|c|c|c|c|}
\hline \multirow{5}{*}{$\begin{array}{l}\text { Empleados } \\
\text { administrativos }\end{array}$} & Muy confiables & 16,5 & 8,4 & 13,8 & 11,1 \\
\hline & Algo confiables & 57,2 & 49,6 & 55,9 & 52,3 \\
\hline & Poco confiables & 12,7 & 19,6 & 18,6 & 17,8 \\
\hline & Nada confiables & 3,0 & 3,0 & 1,4 & 2,8 \\
\hline & No los conoce & 10,6 & 19,4 & 10,3 & 16,0 \\
\hline \multirow{5}{*}{$\begin{array}{l}\text { Organizaciones y } \\
\text { colectivos estudiantiles }\end{array}$} & Muy confiables & 9,0 & 5,0 & 4,2 & 5,8 \\
\hline & Algo confiables & 43,2 & 47,1 & 36,1 & 44,6 \\
\hline & Poco confiables & 29,1 & 24,4 & 31,3 & 26,5 \\
\hline & Nada confiables & 6,4 & 6,1 & 4,9 & 6,0 \\
\hline & No los conoce & 12,4 & 17,4 & 23,6 & 17,1 \\
\hline \multirow{5}{*}{$\begin{array}{l}\text { Organizaciones de } \\
\text { jubilados }\end{array}$} & Muy confiables & 15,3 & 3,8 & 6,9 & 6,9 \\
\hline & Algo confiables & 40,7 & 37,1 & 33,8 & 37,5 \\
\hline & Poco confiables & 16,1 & 14,9 & 18,6 & 15,7 \\
\hline & Nada confiables & 0,4 & 3,1 & 2,1 & 2,3 \\
\hline & No los conoce & 27,5 & 41,2 & 38,6 & 37,6 \\
\hline \multirow{5}{*}{$\begin{array}{l}\text { Organizaciones de } \\
\text { empleados no docentes }\end{array}$} & Muy confiables & 10,6 & 3,3 & 4,8 & 5,2 \\
\hline & Algo confiables & 43,0 & 40,5 & 39,3 & 40,9 \\
\hline & Poco confiables & 17,4 & 16,6 & 21,4 & 17,5 \\
\hline & Nada confiables & 0,9 & 3,7 & 2,8 & 2,9 \\
\hline & No los conoce & 28,1 & 35,9 & 31,7 & 33,5 \\
\hline \multirow{5}{*}{$\begin{array}{l}\text { Vigilantes de la } \\
\text { Universidad }\end{array}$} & Muy confiables & 9,4 & 7,7 & 6,9 & 8,0 \\
\hline & Algo confiables & 42,6 & 43,7 & 39,6 & 42,8 \\
\hline & Poco confiables & 33,6 & 28,8 & 41,7 & 31,8 \\
\hline & Nada confiables & 6,8 & 13,1 & 5,6 & 10,6 \\
\hline & No los conoce & 7,7 & 6,7 & 6,3 & 6,9 \\
\hline \multirow[t]{5}{*}{ Profesores } & Muy confiables & 28,0 & 25,4 & 24,5 & 25,9 \\
\hline & Algo confiables & 66,1 & 65,6 & 60,5 & 65,0 \\
\hline & Poco confiables & 4,2 & 7,4 & 8,8 & 6,9 \\
\hline & Nada confiables & 1,3 & 1,1 & 0,7 & 1,1 \\
\hline & No los conoce & 0,4 & 0,5 & 5,4 & 1,2 \\
\hline
\end{tabular}


Tabla 5. (Continuación)

\begin{tabular}{|l|l|c|c|c|c|}
\hline Investigadores & Muy confiables & 22,6 & 26,3 & 16,6 & 24,0 \\
\cline { 2 - 6 } & Algo confiables & 63,2 & 50,2 & 53,1 & 53,6 \\
\cline { 2 - 6 } & Poco confiables & 8,5 & 7,6 & 11,0 & 8,3 \\
\cline { 2 - 6 } & Nada confiables & 0,9 & 1,3 & 0,7 & 1,1 \\
\cline { 2 - 6 } & No los conoce & 4,7 & 14,6 & 18,6 & 12,9 \\
\hline
\end{tabular}

Fuente: elaboración propia.

Finalmente, la percepción que se tiene sobre el nivel de involucramiento que tienen los diferentes actores en la resolución de los problemas de la Universidad no se encuentra desligada a la lectura anterior, ya que, en términos generales, la apreciación sobre el papel activo de estos en las problemáticas universitarias es considerado mayoritariamente alto por todos los estamentos, salvo a los administrativos y a los otros empleados a quienes les asignan un papel más pasivo. Por estamentos, las diferencias que vale la pena resaltar se encuentran nuevamente entre empleados y estudiantes. Los primeros valoran mucho más el papel de actores individuales como el Rector y los decanos

[266] en este rol, mientras que los segundos valoran más a los cuerpos colegiados como los consejos Superior y Académico y a los profesores (véase tabla 6).

Tabla 6. Compromiso de actores universitarios en la solución de problemas de la Universidad. Porcentaje por estamentos.

\begin{tabular}{|l|l|c|c|c|c|}
\hline \multicolumn{2}{|c|}{ Variable } & \multicolumn{4}{c|}{ ¿Qué tan involucrados están? } \\
\cline { 3 - 6 } & Profesor & Estudiante & Empleado & Total \\
\hline \multirow{4}{*}{$\begin{array}{l}\text { Consejo Superior } \\
\text { Universitario }\end{array}$} & Muy involucrados & 21,3 & 18,8 & 29,2 & 20,9 \\
\cline { 2 - 6 } & Algo involucrados & 44,3 & 54,4 & 40,3 & 49,9 \\
\cline { 2 - 6 } & Poco involucrados & 29,8 & 23,8 & 25,0 & 25,4 \\
\cline { 2 - 6 } & Nada involucrados & 4,7 & 3,0 & 5,6 & 3,7 \\
\hline \multirow{4}{*}{ Consejo Académico } & Muy involucrados & 20,4 & 20,1 & 30,3 & 21,6 \\
\cline { 2 - 6 } & Algo involucrados & 45,8 & 56,9 & 44,4 & 52,4 \\
\cline { 2 - 6 } & Poco involucrados & 28,8 & 19,6 & 21,8 & 22,1 \\
\cline { 2 - 6 } & Nada involucrados & 5,0 & 3,5 & 3,5 & 3,8 \\
\hline
\end{tabular}


Representaciones sobre la democracia, las instituciones y los actores gubernamentales...

Tabla 6. (Continuación)

\begin{tabular}{|c|c|c|c|c|c|}
\hline \multirow[t]{4}{*}{ Rector } & Muy involucrados & 30,9 & 24,1 & 41,8 & 28,3 \\
\hline & Algo involucrados & 42,1 & 46,5 & 33,3 & 43,5 \\
\hline & Poco involucrados & 21,5 & 22,7 & 19,9 & 22,0 \\
\hline & Nada involucrados & 5,6 & 6,7 & 5,0 & 6,2 \\
\hline \multirow[t]{4}{*}{ Decanos } & Muy involucrados & 22,3 & 21,1 & 33,8 & 23,2 \\
\hline & Algo involucrados & 46,6 & 53,5 & 42,1 & 50,2 \\
\hline & Poco involucrados & 24,8 & 21,7 & 20,7 & 22,3 \\
\hline & Nada involucrados & 6,3 & 3,7 & 3,4 & 4,3 \\
\hline \multirow{4}{*}{$\begin{array}{l}\text { Jefes de } \\
\text { Departamentos, } \\
\text { Escuelas o Institutos }\end{array}$} & Muy involucrados & 15,6 & 16,0 & 22,4 & 16,8 \\
\hline & Algo involucrados & 44,7 & 58,0 & 46,3 & 53,1 \\
\hline & Poco involucrados & 28,7 & 21,7 & 23,1 & 23,5 \\
\hline & Nada involucrados & 11,0 & 4,4 & 8,2 & 6,5 \\
\hline \multirow[t]{4}{*}{ Administrativos } & Muy involucrados & 6,3 & 8,3 & 9,5 & 8,0 \\
\hline & Algo involucrados & 39,3 & 49,2 & 45,6 & 46,3 \\
\hline & Poco involucrados & 41,0 & 32,7 & 39,5 & 35,7 \\
\hline & Nada involucrados & 13,4 & 9,8 & 5,4 & 10,0 \\
\hline \multirow[t]{4}{*}{ Otros empleados } & Muy involucrados & 3,9 & 3,8 & 6,2 & 4,2 \\
\hline & Algo involucrados & 27,9 & 37,5 & 30,1 & 34,1 \\
\hline & Poco involucrados & 49,4 & 44,2 & 52,1 & 46,6 \\
\hline & Nada involucrados & 18,9 & 14,5 & 11,6 & 15,1 \\
\hline \multirow{4}{*}{$\begin{array}{l}\text { Profesores- } \\
\text { investigadores }\end{array}$} & Muy involucrados & 15,7 & 24,5 & 25,0 & 22,5 \\
\hline & Algo involucrados & 45,9 & 55,5 & 50,7 & 52,5 \\
\hline & Poco involucrados & 34,7 & 17,0 & 20,8 & 21,8 \\
\hline & Nada involucrados & 3,7 & 3,0 & 3,5 & 3,3 \\
\hline
\end{tabular}

Fuente: elaboración propia.

El tercer y último componente engloba entre sus variables principales dos categorías, la percepción sobre las diferentes formas de participación de los ciudadanos y el papel del Estado en el ordenamiento social y político, indicando que para los encuestados tanto el accionar de los primeros y del segundo están imbricados o son complementarios. La tabla 7 muestra la magnitud de estas correlaciones, donde las principales variables —o las de mayor correlación - en el ámbito de la participación dan cuenta de la percepción sobre las diferentes formas de protesta, las formas organizativas, el empoderamiento en los temas políticos y las diferentes formas de participación 
—formales e informales—. En relación con el papel del Estado, aquí confluyen diversas opiniones, como la necesidad de que este intervenga en el sector económico y político, y sobre los medios de comunicación; adicional a esto, también se encuentra diversas opiniones sobre un Estado fuerte que pueda responder a las contingencias mediante la acción del presidente. ${ }^{3}$

Tabla 7. Percepción de la acción ciudadana y el papel del Estado. De acuerdo o en desacuerdo con las siguientes afirmaciones.

\begin{tabular}{|l|c|}
\hline \multicolumn{1}{|c|}{ Variable } & $\begin{array}{c}\text { Correlación con el } \\
\text { tercer componente }\end{array}$ \\
\hline $\begin{array}{l}\text { Que las personas destruyan los bienes públicos como forma de } \\
\text { protesta }\end{array}$ & 0,510 \\
\hline Que el Estado garantice la participación de las minorías en política & $-0,480$ \\
\hline $\begin{array}{l}\text { El Estado colombiano, más que el sector privado, debería ocuparse } \\
\text { de que todas las personas tengan sus necesidades básicas satisfechas } \\
\text { (salud, educación, vivienda, recreación) }\end{array}$ & $-0,468$ \\
\hline $\begin{array}{l}\text { Que las personas destruyan la propiedad privada como forma de } \\
\text { protesta }\end{array}$ & 0,460 \\
\hline $\begin{array}{l}\text { En momentos difíciles el presidente puede cerrar el Congreso y } \\
\text { gobernar sin él }\end{array}$ & 0,454 \\
\hline $\begin{array}{l}\text { En momentos difíciles el presidente puede disolver la Corte } \\
\text { Constitucional y gobierne sin ella }\end{array}$ & 0,453 \\
\hline $\begin{array}{l}\text { Es justificable que se utilice la fuerza para solucionar un conflicto } \\
\text { político que está afectando a muchas personas }\end{array}$ & 0,441 \\
\hline $\begin{array}{l}\text { El Estado colombiano debe implementar políticas firmes para reducir } \\
\text { la desigualdad de ingresos entre ricos y pobres. }\end{array}$ & $-0,433$ \\
\hline Confianza en las organizaciones de profesores & $-0,425$ \\
\hline $\begin{array}{l}\text { Que las personas participen en una organización o grupo para tratar } \\
\text { de resolver los problemas comunes }\end{array}$ & $-0,425$ \\
\hline $\begin{array}{l}\text { Las personas como usted NO tienen nada que opinar sobre lo que } \\
\text { hace el gobierno }\end{array}$ & 0,424 \\
\hline $\begin{array}{l}\text { Es preferible sacrificar algunas libertades de expresión a cambio de } \\
\text { vivir sin presiones económicas }\end{array}$ & 0,424 \\
\hline Número de espacios de participación ciudadana que se conoce & 0,413 \\
\hline Es bueno que exista desigualdad para incentivar la competencia & \\
\hline
\end{tabular}

\footnotetext{
${ }^{3}$ Aquí es bueno señalar que el componente encierra otras variables interesantes como se muestra en la tabla 7, pero la baja correlación que poseen con el mismo indica que pueden ser residuales, incluso siendo un poco laxos en la lectura se aceptaron aquellas que tienen una correlación superior al 0,3.
} 
Representaciones sobre la democracia, las instituciones y los actores gubernamentales...

Tabla 7. (Continuación)

\begin{tabular}{|c|c|}
\hline $\begin{array}{l}\text { Los políticos que NO creen en Dios no son adecuados para ocupar } \\
\text { cargos públicos }\end{array}$ & 0,389 \\
\hline $\begin{array}{l}\text { Que las personas invadan la propiedad privada como forma de } \\
\text { protesta }\end{array}$ & 0,368 \\
\hline Que el Estado controle la labor de los medios de comunicación & 0,362 \\
\hline Las elecciones en Colombia son limpias & 0,362 \\
\hline $\begin{array}{l}\text { Que las personas hagan justicia por su propia cuenta cuando el } \\
\text { Estado no castiga a los criminales }\end{array}$ & 0,362 \\
\hline La democracia es preferible a cualquier otra forma de gobierno & $-0,353$ \\
\hline Que cualquier persona pueda acceder a cargos de elección popular & $-0,339$ \\
\hline $\begin{array}{l}\text { El Estado colombiano, en lugar del sector privado, debería ser el } \\
\text { dueño de las empresas e industrias más importantes del país }\end{array}$ & $-0,339$ \\
\hline $\begin{array}{l}\text { Las personas se interesan en conocer acerca de las tareas que el } \\
\text { Gobierno realiza }\end{array}$ & 0,339 \\
\hline $\begin{array}{l}\text { La política algunas veces es tan complicada que las personas como } \\
\text { usted NO entienden lo que sucede }\end{array}$ & 0,335 \\
\hline $\begin{array}{l}\text { La competencia electoral entre los partidos es mala porque gana } \\
\text { quien no se lo merece }\end{array}$ & 0,334 \\
\hline $\begin{array}{l}\text { El Estado colombiano, más que la empresa privada, debería ser el } \\
\text { principal responsable de crear empleos }\end{array}$ & $-0,315$ \\
\hline $\begin{array}{l}\text { Que las personas trabajen en campañas electorales para un partido } \\
\text { político o candidato }\end{array}$ & $-0,312$ \\
\hline Número de espacios de participación ciudadana usados & 0,308 \\
\hline $\begin{array}{l}\text { Los líderes religiosos NO deberían tener influencia en las decisiones } \\
\text { del Gobierno }\end{array}$ & $-0,306$ \\
\hline $\begin{array}{l}\text { En general, los hombres son mejores líderes políticos que las } \\
\text { mujeres }\end{array}$ & 0,303 \\
\hline Número de mecanismos de participación ciudadana usados & 0,302 \\
\hline Usted se interesa mucho, algo, poco o nada en la política & $-0,299$ \\
\hline En elecciones, usted siempre vota, a veces vota o nunca vota & $-0,297$ \\
\hline Confianza en los estudiantes & $-0,291$ \\
\hline Personas con las que habla de política & 0,280 \\
\hline El gobierno protege la libertad individual & 0,279 \\
\hline $\begin{array}{l}\text { En Colombia las personas son capaces de escuchar a otras con ideas } \\
\text { distintas a las suyas }\end{array}$ & 0,272 \\
\hline Número de instrumentos de protección de derechos que ha usado & 0,266 \\
\hline Confianza en su comunidad & $-0,247$ \\
\hline
\end{tabular}


Tabla 7. (Continuación)

\begin{tabular}{|l|c|}
\hline $\begin{array}{l}\text { A las personas del gobierno NO les interesa mucho lo que las } \\
\text { personas como usted piensan }\end{array}$ & $-0,229$ \\
\hline Número de instrumentos de protección de derechos que conoce & 0,229 \\
\hline En cuantos grupos participa o ha participado & 0,222 \\
\hline $\begin{array}{l}\text { El Estado debe exigir que los partidos políticos reserven algunos } \\
\text { espacios para mujeres en sus listas de candidatos, aunque tengan } \\
\text { que dejar fuera a algunos hombres }\end{array}$ & $-0,217$ \\
\hline $\begin{array}{l}\text { Que las personas invadan el espacio público como forma de } \\
\text { protesta }\end{array}$ & 0,213 \\
\hline $\begin{array}{l}\text { El voto es la única manera para opinar sobre lo que hace el } \\
\text { Gobierno }\end{array}$ & 0,211 \\
\hline Número de mecanismos de participación ciudadana que se conoce & 0,205 \\
\hline $\begin{array}{l}\text { Disposición a pagar más impuestos si se usaran para darle más a } \\
\text { quien tiene menos }\end{array}$ & 0,201 \\
\hline Las personas se reúnen para hablar de política & 0,191 \\
\hline $\begin{array}{l}\text { Pensando en su seguridad y la de su familia, iusted se siente más } \\
\text { seguro(a), igual de seguro(a), o menos seguro(a) que hace cinco } \\
\text { años? }\end{array}$ & 0,191 \\
\hline $\begin{array}{l}\text { Las personas en la Universidad se interesan en conocer acerca de las } \\
\text { tareas que el Gobierno realiza }\end{array}$ & 0,190 \\
\hline Compromiso de los estudiantes & 0,162 \\
\hline Cantidad de medios de información usados & 0,155 \\
\hline
\end{tabular}

Fuente: elaboración propia.

Otra de las características que se presentan en este componente es que muchas de estas variables auscultan la percepción sobre el uso de la fuerza como mecanismo de participación y de un Estado autoritario; sin embargo, su aceptación no se constituye en mayoría en el claustro universitario, al contrario, su correlación da cuenta de un imaginario más consensual. Como se ha visto hasta ahora, a pesar de la alta desconfianza en las instituciones, no se acepta de manera generalizada el uso de la fuerza, la ruptura del equilibrio de poderes y la censura, algo que está en consonancia con los requisitos que las personas consideran necesarios en una democracia. Ahora bien, en una lectura detallada sobre las percepciones, se puede inferir que este perfil autoritario es más recurrente entre los estudiantes —que entre profesores y empleados - , quienes aceptan que es posible hacer uso de la fuerza o destruir los bienes públicos o privados como medida de protesta, incluso como forma de acción del Estado (véase tabla 8). 
Representaciones sobre la democracia, las instituciones y los actores gubernamentales...

Tabla 8. Percepción de la acción ciudadana y el papel del Estado. De acuerdo o en desacuerdo con las siguientes afirmaciones. Porcentaje por estamentos.

\begin{tabular}{|c|c|c|c|c|c|}
\hline Variable & Respuesta & Profesor & Estudiante & Empleado & Total \\
\hline \multirow{4}{*}{$\begin{array}{l}\text { Destruyan los bienes } \\
\text { públicos como forma de } \\
\text { protesta }\end{array}$} & Muy de acuerdo & 0,8 & 0,5 & 0,7 & 0,6 \\
\hline & De acuerdo & 2,5 & 15,8 & 2,7 & 10,8 \\
\hline & En desacuerdo & 31,8 & 37,0 & 35,1 & 35,5 \\
\hline & Muy en desacuerdo & 64,9 & 46,8 & 61,5 & 53,2 \\
\hline \multirow{4}{*}{$\begin{array}{l}\text { Que las personas } \\
\text { destruyan la propiedad } \\
\text { privada como forma de } \\
\text { protesta }\end{array}$} & Muy de acuerdo & 1,7 & 0,5 & 0,0 & 0,7 \\
\hline & De acuerdo & 3,7 & 12,5 & 1,4 & 8,8 \\
\hline & En desacuerdo & 37,6 & 42,7 & 37,8 & 40,8 \\
\hline & Muy en desacuerdo & 57,0 & 44,3 & 60,8 & 49,7 \\
\hline \multirow{4}{*}{$\begin{array}{l}\text { Que las personas invadan } \\
\text { la propiedad privada } \\
\text { como forma de protesta }\end{array}$} & Muy de acuerdo & 2,1 & 3,2 & 1,4 & 2,6 \\
\hline & De acuerdo & 8,8 & 21,8 & 4,7 & 16,3 \\
\hline & En desacuerdo & 43,3 & 50,7 & 45,3 & 48,2 \\
\hline & Muy en desacuerdo & 45,8 & 24,3 & 48,6 & 32,9 \\
\hline \multirow{4}{*}{$\begin{array}{l}\text { Que las personas hagan } \\
\text { justicia por su propia } \\
\text { cuenta cuando el } \\
\text { Estado no castiga a los } \\
\text { criminales. }\end{array}$} & Muy de acuerdo & 1,7 & 5,2 & 2,7 & 4,0 \\
\hline & De acuerdo & 7,1 & 27,4 & 8,1 & 19,8 \\
\hline & En desacuerdo & 47,7 & 42,6 & 49,3 & 44,7 \\
\hline & Muy en desacuerdo & 43,5 & 24,8 & 39,9 & 31,4 \\
\hline \multirow{4}{*}{$\begin{array}{l}\text { Es justificable que se } \\
\text { utilice la fuerza para } \\
\text { solucionar un conflicto } \\
\text { político que está } \\
\text { afectando a muchas } \\
\text { personas }\end{array}$} & Muy de acuerdo & 3,3 & 2,9 & 2,7 & 3,0 \\
\hline & De acuerdo & 19,2 & 23,8 & 15,6 & 21,6 \\
\hline & En desacuerdo & 39,3 & 46,8 & 46,3 & 45,0 \\
\hline & Muy en desacuerdo & 38,1 & 26,5 & 35,4 & 30,5 \\
\hline \multirow{4}{*}{$\begin{array}{l}\text { En momentos difíciles el } \\
\text { presidente del país puede } \\
\text { cerrar el Congreso y } \\
\text { gobernar sin él }\end{array}$} & Muy de acuerdo & 3,0 & 2,2 & 0,7 & 2,2 \\
\hline & De acuerdo & 9,4 & 18,5 & 6,5 & 14,6 \\
\hline & En desacuerdo & 37,4 & 42,3 & 46,0 & 41,7 \\
\hline & Muy en desacuerdo & 50,2 & 37,0 & 46,8 & 41,6 \\
\hline \multirow{4}{*}{$\begin{array}{l}\text { En momentos difíciles } \\
\text { el presidente del país } \\
\text { puede disolver la Corte } \\
\text { Constitucional y gobierne } \\
\text { sin ella }\end{array}$} & Muy de acuerdo & 2,5 & 0,7 & 2,9 & 1,4 \\
\hline & De acuerdo & 10,2 & 17,3 & 7,9 & 14,2 \\
\hline & En desacuerdo & 36,9 & 49,3 & 47,1 & 46,0 \\
\hline & Muy en desacuerdo & 50,4 & 32,7 & 42,1 & 38,4 \\
\hline
\end{tabular}


Tabla 8. (Continuación)

\begin{tabular}{|l|l|c|c|c|c|}
\hline \multirow{2}{*}{$\begin{array}{l}\text { Que el Estado controle } \\
\text { la labor de los medios de } \\
\text { comunicación }\end{array}$} & Muy de acuerdo & 9,1 & 4,0 & 8,2 & 5,8 \\
\cline { 2 - 6 } & De acuerdo & 20,7 & 19,3 & 22,4 & 20,1 \\
\cline { 2 - 6 } & En desacuerdo & 45,2 & 48,2 & 49,7 & 47,7 \\
\cline { 2 - 6 } & Muy en desacuerdo & 24,9 & 28,5 & 19,7 & 26,4 \\
\hline \multirow{2}{*}{$\begin{array}{l}\text { Es preferible sacrificar } \\
\text { algunas libertades de } \\
\text { expresión a cambio } \\
\text { de vivir sin presiones } \\
\text { económica }\end{array}$} & Muy de acuerdo & 4,6 & 2,3 & 2,7 & 2,9 \\
\cline { 2 - 6 } & De acuerdo & 8,8 & 14,4 & 21,9 & 14,1 \\
\cline { 2 - 6 } & En desacuerdo & 48,3 & 54,0 & 41,8 & 50,9 \\
\cline { 2 - 6 } $\begin{array}{l}\text { Que las personas invadan } \\
\text { el espacio público como } \\
\text { forma de protesta }\end{array}$ & Muy en desacuerdo & 38,3 & 29,3 & 33,6 & 32,1 \\
\cline { 2 - 6 } & Muy de acuerdo & 6,2 & 13,7 & 5,4 & 10,8 \\
\cline { 2 - 6 } & De acuerdo & 27,8 & 50,7 & 21,6 & 41,1 \\
\hline & En desacuerdo & 39,0 & 25,0 & 39,2 & 30,3 \\
\cline { 2 - 6 } & Muy en desacuerdo & 27,0 & 10,6 & 33,8 & 17,8 \\
\hline \multirow{2}{*}{$\begin{array}{l}\text { Que las personas hagan } \\
\text { justicia por su propia } \\
\text { cuenta cuando el } \\
\text { Estado no castiga a los } \\
\text { criminales. }\end{array}$} & Muy de acuerdo & 1,7 & 5,2 & 2,7 & 4,0 \\
\cline { 2 - 6 } & De acuerdo & 7,1 & 27,4 & 8,1 & 19,8 \\
\cline { 2 - 6 } & En desacuerdo & 47,7 & 42,6 & 49,3 & 44,7 \\
\cline { 2 - 6 } & Muy en desacuerdo & 43,5 & 24,8 & 39,9 & 31,4 \\
\hline
\end{tabular}

Fuente: elaboración propia.

De otro lado, las percepciones y la acción política de los universitarios comprenden múltiples dimensiones: el ámbito electoral no es el principal medio de acción, ya que gran parte desconfía de su legitimidad como forma de opinión sobre lo que realiza el Gobierno; además, los universitarios reconocen la existencia de otros mecanismos y espacios de participación ciudadana. De igual modo, los diferentes estamentos declaran alto interés hacia los temas políticos, aunque esto no se ve reflejado cuando se les pregunta por los procesos de discusión que puedan plantearse o el interés que los demás puedan tener al respecto, ya que sienten que es muy difícil que se acepte la pluralidad de opiniones, tanto en la Universidad como fuera de ella. Es por eso que no se percibe que las personas discutan sobre política o, incluso, que sea un tema recurrente en sus vidas diarias (véase número de personas con las que se habla de política). Este componente hasta ahora enseña que las actitudes autoritarias y el descontento hacia los procesos políticos conllevan a que este tema se desarrolle en un ámbito privado y que las percepciones sean escasamente compartidas entre grupos (véase tabla 9). 
Representaciones sobre la democracia, las instituciones y los actores gubernamentales...

Tabla 9. Percepción de la acción política en la Universidad. De acuerdo o en desacuerdo con las siguientes afirmaciones. Porcentaje por estamentos.

\begin{tabular}{|c|c|c|c|c|c|}
\hline Variable & Respuesta & Profesor & Estudiante & Empleado & Total \\
\hline \multirow{4}{*}{$\begin{array}{l}\text { Las elecciones en } \\
\text { Colombia son limpias }\end{array}$} & Muy de acuerdo & 2,6 & 0,3 & 0,0 & 0,8 \\
\hline & De acuerdo & 8,6 & 13,2 & 3,6 & 10,7 \\
\hline & En desacuerdo & 42,5 & 47,5 & 54,3 & 47,3 \\
\hline & Muy en desacuerdo & 46,4 & 39,0 & 42,1 & 41,2 \\
\hline \multirow{4}{*}{$\begin{array}{l}\text { La competencia electoral } \\
\text { entre los partidos es mala } \\
\text { porque gana quien no se lo } \\
\text { merece }\end{array}$} & Muy de acuerdo & 5,5 & 5,2 & 6,4 & 5,4 \\
\hline & De acuerdo & 19,1 & 30,5 & 29,3 & 27,6 \\
\hline & En desacuerdo & 52,8 & 46,9 & 42,9 & 47,7 \\
\hline & Muy en desacuerdo & 22,6 & 17,4 & 21,4 & 19,2 \\
\hline \multirow{4}{*}{$\begin{array}{l}\text { El voto es la única manera } \\
\text { que las personas tienen } \\
\text { para opinar sobre lo que } \\
\text { hace el Gobierno }\end{array}$} & Muy de acuerdo & 17,4 & 11,3 & 12,8 & 13,0 \\
\hline & De acuerdo & 21,9 & 27,4 & 23,0 & 25,4 \\
\hline & En desacuerdo & 40,1 & 38,7 & 41,2 & 39,4 \\
\hline & Muy en desacuerdo & 20,7 & 22,6 & 23,0 & 22,2 \\
\hline \multirow{4}{*}{$\begin{array}{l}\text { Las personas NO tienen } \\
\text { nada que opinar sobre lo } \\
\text { que hace el Gobierno }\end{array}$} & Muy de acuerdo & 0,8 & 2,1 & 2,0 & 1,8 \\
\hline & De acuerdo & 8,8 & 16,0 & 8,8 & 13,2 \\
\hline & En desacuerdo & 48,8 & 44,2 & 58,1 & 47,3 \\
\hline & Muy en desacuerdo & 41,7 & 37,7 & 31,1 & 37,7 \\
\hline \multirow{4}{*}{$\begin{array}{l}\text { Las personas en Colombia } \\
\text { se interesan en conocer } \\
\text { las tareas que el Gobierno } \\
\text { realiza }\end{array}$} & Muy de acuerdo & 1,3 & 1,1 & 0,0 & 1,0 \\
\hline & De acuerdo & 18,4 & 21,0 & 16,9 & 19,8 \\
\hline & En desacuerdo & 57,7 & 53,3 & 65,5 & 56,1 \\
\hline & Muy en desacuerdo & 22,6 & 24,6 & 17,6 & 23,1 \\
\hline \multirow{4}{*}{$\begin{array}{l}\text { La política algunas veces } \\
\text { es tan complicada que las } \\
\text { personas como usted NO } \\
\text { entienden lo que sucede. }\end{array}$} & Muy de acuerdo & 5,0 & 6,7 & 10,1 & 6,8 \\
\hline & De acuerdo & 15,8 & 29,5 & 29,1 & 26,2 \\
\hline & En desacuerdo & 45,8 & 45,2 & 42,6 & 45,0 \\
\hline & Muy en desacuerdo & 33,3 & 18,6 & 18,2 & 22,0 \\
\hline \multirow{4}{*}{$\begin{array}{l}\text { ¿Usted es una persona que } \\
\text { se interesa mucho, algo, } \\
\text { poco o nada en la política? }\end{array}$} & Mucho & 26,0 & 13,1 & 15,0 & 16,5 \\
\hline & Algo & 42,1 & 42,4 & 39,5 & 41,9 \\
\hline & Poco & 24,4 & 33,2 & 28,6 & 30,5 \\
\hline & Nada & 7,4 & 11,2 & 17,0 & 11,2 \\
\hline \multirow{4}{*}{$\begin{array}{l}\text { Las personas en Colombia } \\
\text { son capaces de escuchar a } \\
\text { otras con ideas distintas a } \\
\text { las suyas }\end{array}$} & Muy de acuerdo & 1,7 & 3,5 & 2,7 & 2,9 \\
\hline & De acuerdo & 18,3 & 27,8 & 31,5 & 26,1 \\
\hline & En desacuerdo & 62,2 & 58,3 & 58,2 & 59,2 \\
\hline & Muy en desacuerdo & 17,8 & 10,4 & 7,5 & 11,8 \\
\hline
\end{tabular}


Tabla 9. (Continuación)

\begin{tabular}{|c|c|c|c|c|c|}
\hline \multirow{4}{*}{$\begin{array}{l}\text { Las personas en la } \\
\text { Universidad se interesan en } \\
\text { conocer las tareas que el } \\
\text { Gobierno realiza }\end{array}$} & Muy de acuerdo & 5,1 & 7,1 & 2,0 & 5,9 \\
\hline & De acuerdo & 39,7 & 56,3 & 44,9 & 50,7 \\
\hline & En desacuerdo & 47,7 & 30,3 & 42,9 & 36,2 \\
\hline & Muy en desacuerdo & 7,6 & 6,3 & 10,2 & 7,2 \\
\hline \multirow{3}{*}{$\begin{array}{l}\text { Personas con las que habla } \\
\text { de política }\end{array}$} & Ninguna & 12,0 & 21,0 & 34,5 & 20,8 \\
\hline & Algunas personas & 77,7 & 72,4 & 60,1 & 71,9 \\
\hline & Muchas personas & 10,3 & 6,6 & 5,4 & 7,3 \\
\hline \multirow{4}{*}{$\begin{array}{l}\text { Número de grupos en que } \\
\text { participa o ha participado }\end{array}$} & Ninguno & 30,2 & 43,5 & 49,3 & 41,2 \\
\hline & Entre uno y cuatro & 62,8 & 51,1 & 48,6 & 53,5 \\
\hline & Entre cinco y nueve & 6,2 & 4,9 & 2,0 & 4,8 \\
\hline & Más de diez & 0,8 & 0,5 & 0,0 & 0,5 \\
\hline \multirow{4}{*}{$\begin{array}{l}\text { Número de espacios de } \\
\text { participación ciudadana } \\
\text { que conoce }\end{array}$} & Ninguno & 3,3 & 16,9 & 0,7 & 11,3 \\
\hline & Entre uno y cuatro & 15,7 & 29,5 & 18,9 & 24,7 \\
\hline & Entre cinco y diez & 59,5 & 45,4 & 74,3 & 52,9 \\
\hline & Más de diez & 21,5 & 8,2 & 6,1 & 11,0 \\
\hline \multirow{3}{*}{$\begin{array}{l}\text { Número de mecanismos } \\
\text { de participación ciudadana } \\
\text { usados }\end{array}$} & Ninguno & 66,5 & 77,3 & 82,4 & 75,5 \\
\hline & Entre uno y cuatro & 33,5 & 22,6 & 17,6 & 24,4 \\
\hline & Más de cinco & 0,0 & 0,2 & 0,0 & 0,1 \\
\hline \multirow{3}{*}{$\begin{array}{l}\text { Número de espacios de } \\
\text { participación ciudadana } \\
\text { usados }\end{array}$} & Ninguno & 61,6 & 84,4 & 86,5 & 79,3 \\
\hline & Entre uno y cuatro & 36,8 & 14,8 & 12,8 & 19,7 \\
\hline & Más de cinco & 1,7 & 0,8 & 0,7 & 1,0 \\
\hline \multirow{3}{*}{$\begin{array}{l}\text { Número de instrumentos } \\
\text { de protección de derechos } \\
\text { que ha usado }\end{array}$} & Ninguno & 62,8 & 75,2 & 81,1 & 73,1 \\
\hline & Entre uno y cuatro & 36,8 & 24,4 & 18,9 & 26,6 \\
\hline & Cinco & 0,4 & 0,3 & 0,0 & 0,3 \\
\hline \multirow{3}{*}{$\begin{array}{l}\text { Número de instrumentos } \\
\text { de protección de derechos } \\
\text { que conoce }\end{array}$} & Ninguno & 1,2 & 1,1 & 0,7 & 1,1 \\
\hline & Entre uno y cuatro & 68,6 & 83,8 & 77,7 & 79,3 \\
\hline & Cinco & 30,2 & 15,1 & 21,6 & 19,6 \\
\hline \multirow{3}{*}{$\begin{array}{l}\text { Número de mecanismos } \\
\text { de participación ciudadana } \\
\text { que se conoce }\end{array}$} & Ninguno & 1,2 & 4,6 & 4,1 & 3,7 \\
\hline & Entre uno y cuatro & 42,1 & 61,8 & 57,4 & 56,5 \\
\hline & Más de cinco & 56,6 & 33,6 & 38,5 & 39,7 \\
\hline \multirow[t]{3}{*}{$\begin{array}{l}\text { Cantidad de medios de } \\
\text { información usados }\end{array}$} & $\begin{array}{l}\text { No se informa en } \\
\text { medios }\end{array}$ & 1,2 & 1,6 & 2,0 & 1,6 \\
\hline & En algunos medios & 79,3 & 81,4 & 84,5 & 81,3 \\
\hline & En variados medios & 19,4 & 17,0 & 13,5 & 17,1 \\
\hline
\end{tabular}


Representaciones sobre la democracia, las instituciones y los actores gubernamentales...

Tabla 9. (Continuación)

\begin{tabular}{|l|l|c|c|c|c|}
\hline \multirow{2}{*}{$\begin{array}{l}\text { Las personas en Colombia } \\
\text { se reúnen para hablar de } \\
\text { política }\end{array}$} & Muy de acuerdo & 5,4 & 4,8 & 7,6 & 5,3 \\
\cline { 2 - 6 } & De acuerdo & 38,1 & 40,5 & 37,5 & 39,5 \\
\cline { 2 - 6 } & En desacuerdo & 46,9 & 44,0 & 48,6 & 45,3 \\
\cline { 2 - 6 } & Muy en desacuerdo & 9,6 & 10,8 & 6,3 & 9,9 \\
\hline
\end{tabular}

Fuente: elaboración propia.

Finalmente, la última parte de este componente muestra actitudes mucho más positivas hacia la democracia y el papel ideal de las instituciones. De este modo, se encuentra entre los estamentos - a diferencia de lo anterior - que la democracia es realmente valorada por la mayoría, pero es relacionada con el papel de un Estado garante de derechos y capaz de incidir en el ordenamiento económico y social, de allí que la participación electoral esté más relacionada con estas variables que con las anteriores (véase tabla 10).

Tabla 10. Percepción de la democracia y de las instituciones. De acuerdo o en desacuerdo con las siguientes afirmaciones. Porcentaje por estamentos.

\begin{tabular}{|c|c|c|c|c|c|c|}
\hline Variable & Respuesta & Profesor & Estudiante & Empleado & $\mathrm{Ns} / \mathrm{Nr}$ & Total \\
\hline \multirow{4}{*}{$\begin{array}{l}\text { La democracia } \\
\text { es preferible } \\
\text { a cualquier } \\
\text { otra forma de } \\
\text { gobierno }\end{array}$} & Muy de acuerdo & 24,9 & 18,7 & 25,7 & 0,0 & 21,2 \\
\hline & De acuerdo & 40,9 & 47,7 & 56,3 & 0,0 & 47,3 \\
\hline & En desacuerdo & 25,7 & 28,2 & 11,8 & 0,0 & 25,2 \\
\hline & Muy en desacuerdo & 8,4 & 5,4 & 6,3 & 0,0 & 6,2 \\
\hline \multirow{4}{*}{$\begin{array}{l}\text { Que el Estado } \\
\text { garantice la } \\
\text { participación de } \\
\text { las minorías en } \\
\text { política }\end{array}$} & Muy de acuerdo & 34,0 & 24,2 & 18,2 & 0,0 & 25,6 \\
\hline & De acuerdo & 45,6 & 52,6 & 48,6 & 0,0 & 50,4 \\
\hline & En desacuerdo & 15,8 & 18,5 & 18,9 & 0,0 & 17,9 \\
\hline & Muy en desacuerdo & 4,6 & 4,7 & 14,2 & 0,0 & 6,1 \\
\hline \multirow{4}{*}{$\begin{array}{l}\text { El Estado } \\
\text { Colombiano, } \\
\text { más que el sector } \\
\text { privado, debería } \\
\text { ocuparse de } \\
\text { que todas las } \\
\text { personas tengan } \\
\text { sus necesidades } \\
\text { básicas satisfechas } \\
\text { (salud, educación, } \\
\text { vivienda, } \\
\text { recreación) }\end{array}$} & Muy de acuerdo & 56,8 & 49,6 & 55,1 & 0,0 & 52,1 \\
\hline & De acuerdo & 36,9 & 41,5 & 32,7 & 0,0 & 39,2 \\
\hline & En desacuerdo & 5,8 & 8,1 & 10,9 & 0,0 & 7,9 \\
\hline & Muy en desacuerdo & 0,4 & 0,8 & 1,4 & 0,0 & 0,8 \\
\hline
\end{tabular}


Tabla 10. (Continuación)

\begin{tabular}{|c|c|c|c|c|c|c|}
\hline \multirow{4}{*}{$\begin{array}{l}\text { El Estado } \\
\text { colombiano debe } \\
\text { implementar } \\
\text { políticas firmes } \\
\text { para reducir la } \\
\text { desigualdad de } \\
\text { ingresos entre } \\
\text { ricos y pobres }\end{array}$} & Muy de acuerdo & 49,8 & 42,1 & 49,0 & 0,0 & 44,9 \\
\hline & De acuerdo & 40,7 & 48,8 & 42,2 & 0,0 & 45,9 \\
\hline & En desacuerdo & 9,1 & 8,4 & 8,2 & 0,0 & 8,6 \\
\hline & Muy en desacuerdo & 0,4 & 0,6 & 0,7 & 0,0 & 0,6 \\
\hline \multirow{4}{*}{$\begin{array}{l}\text { Que las personas } \\
\text { participen en } \\
\text { una organización } \\
\text { o grupo para } \\
\text { tratar de resolver } \\
\text { los problemas } \\
\text { comunes }\end{array}$} & Muy de acuerdo & 34,0 & 23,4 & 17,0 & 0,0 & 25,0 \\
\hline & De acuerdo & 42,3 & 50,9 & 49,7 & 0,0 & 48,7 \\
\hline & En desacuerdo & 13,7 & 19,6 & 20,4 & 0,0 & 18,3 \\
\hline & Muy en desacuerdo & 10,0 & 6,2 & 12,9 & 0,0 & 8,0 \\
\hline \multirow{4}{*}{$\begin{array}{l}\text { Que las personas } \\
\text { trabajen en } \\
\text { campañas } \\
\text { electorales } \\
\text { para un partido } \\
\text { político o } \\
\text { candidato }\end{array}$} & Muy de acuerdo & 27,3 & 13,1 & 20,9 & 0,0 & 17,6 \\
\hline & De acuerdo & 43,7 & 54,4 & 66,9 & 0,0 & 53,7 \\
\hline & En desacuerdo & 18,9 & 27,1 & 10,8 & 0,0 & 22,8 \\
\hline & Muy en desacuerdo & 10,1 & 5,4 & 1,4 & 0,0 & 5,9 \\
\hline \multirow{4}{*}{$\begin{array}{l}\text { Que cualquier } \\
\text { persona pueda } \\
\text { acceder a cargos } \\
\text { de elección } \\
\text { popular }\end{array}$} & Muy de acuerdo & 29,0 & 18,5 & 18,5 & 0,0 & 21,0 \\
\hline & De acuerdo & 32,4 & 45,0 & 38,4 & 0,0 & 41,0 \\
\hline & En desacuerdo & 27,8 & 30,0 & 31,5 & 0,0 & 29,7 \\
\hline & Muy en desacuerdo & 10,8 & 6,6 & 11,6 & 0,0 & 8,3 \\
\hline \multirow{4}{*}{$\begin{array}{l}\text { El Estado } \\
\text { colombiano, en } \\
\text { lugar del sector } \\
\text { privado, debería } \\
\text { ser el dueño de } \\
\text { las empresas e } \\
\text { industrias más } \\
\text { importantes del } \\
\text { país }\end{array}$} & Muy de acuerdo & 30,0 & 15,8 & 19,2 & 0,0 & 19,6 \\
\hline & De acuerdo & 34,6 & 34,4 & 32,9 & 0,0 & 34,2 \\
\hline & En desacuerdo & 26,7 & 35,7 & 37,0 & 0,0 & 33,7 \\
\hline & Muy en desacuerdo & 8,8 & 14,1 & 11,0 & 0,0 & 12,4 \\
\hline \multirow{4}{*}{$\begin{array}{l}\text { El Estado } \\
\text { colombiano, más } \\
\text { que la empresa } \\
\text { privada, debería } \\
\text { ser el principal } \\
\text { responsable de } \\
\text { crear empleos }\end{array}$} & Muy de acuerdo & 31,0 & 32,6 & 37,4 & 0,0 & 32,9 \\
\hline & De acuerdo & 46,0 & 52,6 & 40,8 & 0,0 & 49,4 \\
\hline & En desacuerdo & 19,7 & 12,8 & 20,4 & 0,0 & 15,5 \\
\hline & Muy en desacuerdo & 3,3 & 1,9 & 1,4 & 0,0 & 2,2 \\
\hline
\end{tabular}


Representaciones sobre la democracia, las instituciones y los actores gubernamentales...

\begin{tabular}{|l|l|c|c|c|c|c|}
\hline \multirow{2}{*}{$\begin{array}{l}\text { Los líderes } \\
\text { religiosos NO } \\
\text { deberían tener } \\
\text { influencia en las } \\
\text { decisiones del } \\
\text { gobierno }\end{array}$} & Muy de acuerdo & 23,8 & 20,4 & 10,9 & 0,0 & 19,8 \\
\cline { 2 - 7 } & De acuerdo & 23,8 & 31,7 & 28,6 & 0,0 & 29,4 \\
\cline { 2 - 7 } & Muy en desacuerdo & 33,8 & 36,1 & 34,7 & 0,0 & 35,4 \\
\hline $\begin{array}{l}\text { Cuando en } \\
\text { Colombia hay } \\
\text { elecciones, usted }\end{array}$ & Siempre vota & 18,8 & 11,7 & 25,9 & 0,0 & 15,4 \\
\cline { 2 - 7 } & A veces vota & 19,4 & 24,4 & 16,9 & 0,0 & 22,2 \\
\cline { 2 - 7 } & Nunca Vota & 2,9 & 28,7 & 5,4 & 0,0 & 19,2 \\
\hline $\begin{array}{l}\text { El Estado debe } \\
\text { exigir que los } \\
\text { partidos políticos } \\
\text { reserven algunos } \\
\text { espacios para } \\
\text { mujeres en } \\
\text { sus listas de } \\
\text { candidatos, } \\
\text { aunque tengan } \\
\text { que dejar fuera a } \\
\text { algunos hombres }\end{array}$ & En desacuerdo & 29,7 & 28,6 & 26,0 & 0,0 & 28,5 \\
\cline { 2 - 7 } & Muy en desacuerdo acuerdo & 42,3 & 43,0 & 49,3 & 0,0 & 43,7 \\
\cline { 2 - 7 } & Mundo & 22,0 & 18,5 & 0,0 & 22,1 \\
\hline
\end{tabular}

Fuente: elaboración propia.

\section{Consideraciones finales}

Los resultados que arroja esta investigación sobre la cultura política en el ámbito universitario permiten concluir que, pese a la alta apreciación de la democracia como principio, ideal o valor político, existe poca confianza e insatisfacción con el funcionamiento de las instituciones democráticas colombianas. Ahora bien, resulta evidente que la democracia representativa cuenta con una aceptable credibilidad como mejor medio de mandato y de legitimación de un gobierno, y de las elecciones como mecanismo para generar representación en los distintos ámbitos territoriales y en el entorno universitario; pero parece que en el imaginario de algunos estamentos gravitara la idea de que pueden existir formas de gobierno «mejores», que no necesariamente se rigen por los procedimientos democráticos.

Adicionalmente, en la Universidad de Antioquia parecen coexistir una actitud crítica frente a la democracia y una ligera tendencia autoritaria, sobre todo entre los estudiantes, pues son menos enfáticos en rechazar la existencia de un líder fuerte que no sea elegido por votación, presentan mayor 
propensión a apelar al uso de la fuerza para resolver conflictos políticos, son más laxos con la división de poderes y valoran menos la competencia entre partidos.

Los hallazgos insinúan también que es necesario conocer más a fondo el imaginario de aquellos actores que se ven más proclives a la democracia como de aquellos que no, pues persisten preguntas que deben resolverse: por un lado, una parte de los encuestados parece ser más selectivo en términos del contenido de esta forma de gobierno, más allá de la libertad de elección, por lo tanto, es necesario conocer el peso sustantivo que le otorgan —si lo conocen - a cada principio de esta. Por el otro, es necesario comprender las causas del desencanto con la democracia en acción, de lo que tenemos muy poca información todavía, pero que podría ser el soporte de expresiones proclives al autoritarismo, de las que no está eximida la Universidad.

En cuanto a la democracia en la Universidad, los tres estamentos ciertamente legitiman los procedimientos electorales para la elección de su gobierno, pero estos deben estar acompañados por procesos de discusión, de deliberación y de participación en la toma de decisiones sobre el presente y el futuro de la Universidad como proyecto colectivo, del que se consideran

[278] actores participantes y no solo depositarios de medidas tomadas por una élite que se atribuye la capacidad de hacer las propuestas que orienten el proyecto futuro de Universidad, o de aquellos que piensan que la participación es esencial y determinante si y solo si ellos la conducen. Se trataría de una idea de gobierno universitario que fortalece su capacidad de guiar y orientar la vida en común y de ejercer el poder (Dahl, 1961), que involucre en la toma de decisiones las perspectivas e intereses de los distintos actores que coexisten en la Universidad.

En todo caso, lo que estudiantes, profesores y administrativos expresan el reto de pensar la Universidad como un espacio político democrático en el que la comunidad política se ve a sí misma con la capacidad y la responsabilidad de participar en la construcción de su propio orden y en la orientación del destino de la institución. Se trata de actores universitarios que legitiman los procedimientos institucionales para la tramitación de los problemas y para la elección de autoridades académicas, pero mantienen las distancias necesarias frente a quienes ejercen el poder y las decisiones que toman. Parece constatarse una deslegitimación de la democracia basada 
Representaciones sobre la democracia, las instituciones y los actores gubernamentales...

en la representación indirecta — autoridades designadas - y que estaría en ciernes una suerte de retorno a la autonomía y a la autorrepresentación como características de una democracia universitaria que, parafraseando a algunos autores, se encuentra en estado de mutación (Cheresky, 2012) o de metamorfosis (Manin, 1995).

\section{Referencias bibliográficas}

1. Almond, Gabriel y Verba, Sidney. (1963). La cultura cívica. Un estudio sobre la participación política democrática en cinco naciones. Madrid: Suramérica.

2. Almond, Gabriel y Verba, Sidney. (1992). La cultura política. En: Batlle, Albert (coord.). Diez textos básicos de ciencia política (pp. 171-230). Barcelona: Ariel.

3. Álvarez Loera, Ana Cecilia y Camacho Sandoval, Salvador. (2009, 21-25 de septiembre). La cultura política de los estudiantes de la Universidad Autónoma de Aguascalientes: entre la conciencia y el cinismo. x Congreso Nacional de Investigación Educativa. Consejo Mexicano de Investigación Educativa, Veracruz. Recuperado de http://www.comie.org.mx/congreso/memoriaelectronica/v10/pdf/area_tematica_06/ ponencias/0738-F.pdf

4. Bermúdez, Emilia; Martínez, Gildardo y Sánchez, Natalia. (2009). Las jóvenes y los jóvenes Universitarios en Venezuela: prácticas discursivas y construcción de representaciones de Identidades políticas. Cuadernos de Cendes, 26 (70), pp. 69-97.

5. Castaño Vélez, Elkin y Moreno, Hernando. (1994). Metodología estadística del modelo de ponderaciones del sistema de selección de beneficiarios de programas sociales (Sisben). Bogotá, D. C.: DNP.

6. Cheresky, Isidoro (comp.). (2012). Mutación democrática: otras ciudadanías, otras representaciones. En: ¿Qué democracia en América Latina? (pp. 23-54). Buenos Aires: Clacso, Prometeo.

7. Crespo, José Antonio. (1988). Niveles de información política en los universitarios mexicanos. Foro Internacional, 114, pp. 319-337.

8. Cubides, Humberto; Laverde, María Cristina y Valderrama, Carlos. (coord.). (1998). "Viviendo a toda». Jóvenes, territorios culturales y nuevas sensibilidades. Bogotá, D. C.: Universidad Central, Siglo del Hombre.

9. Dahl, Robert. (1961). Who Governs? Democracy and Power in an American City. New Haven: Yale University.

10. Díaz Gómez, Álvaro; Carmona, Olga y Salamanca, Liliana. (2011). El método: una experiencia de investigación sobre emergencia de sujetos políticos en jóvenes universitarios. En: Zarzuri, Raúl. (comp.). Jóvenes, participación y construcción de nuevas ciudadanías. Santiago: CESC.

11. Durand Ponte, Víctor Manuel. (2002). Formación cívica de los estudiantes en la UNAM. México, D. F.: UNAM. 
12. Echegaray, Fabián. (1990). Universitarios y política en el Brasil electoral. Nueva Sociedad, 110, pp. 24-34.

13. González, Roberto et al. (2005). Identidad y actitudes políticas en jóvenes universitarios: El desencanto de los que no se identifican políticamente. Revista de Ciencia Política, 25 (2), pp. 65-90. https://doi.org/10.4067/S0718090X2005000200003

13. Henao, Juanita; Ocampo, Angélica; Robledo, Ángela y Lozano, Martha. (2008). Los grupos juveniles universitarios y la formación ciudadana. Universitas Psycholigica, 7 (3), pp. 853-867.

14. Heras Gómez, Leticia. (2002). Cultura política: el estado del arte contemporáneo. Convergencia, 30. Recuperado de https://convergencia.uaemex.mx/ article/view/1675

15. Hernández, Jorge (coord.). (2007). Ciudadanías diferenciadas en un estado multicultural: los usos y costumbres en Oaxaca. Oaxaca: Siglo xxI.

16. Inglehart, Robert. (1988). Cultura política y democracia estable. Revista Española de Investigaciones Sociológicas, 42, pp. 45-65. https://doi.org/10.2307/40183326

17. Jaramillo, Ángela María. (2012). Cultura y participación política en jóvenes universitarios javerianos: una mirada analítica desde jóvenes para jóvenes. Bogotá, D. C.: Pontificia Universidad Javeriana.

18. López Montiel, Ángel Gustavo. (2008). Las teorías de sistemas en el estudio de la cultura política. Política y Cultura, 29, pp. 171-190.

[280] 19. Manin, Bernard. (1995). Los principios del gobierno representativo. Madrid: Alianza.

20. Mendoza, Leticia; Lorenzo, Oswaldo; Flórez, Mirta y Mendoza, Adda. (2011). Cultura y opinión política en estudiantes universitarias del estado de Yucatán, México. Revista Internacional de Ciencias Sociales y Humanidades, xxI (1), pp. 85-103.

21. Morán, María Luz. (1999). Los estudios de cultura política en España. Revista Española de Investigaciones Sociológicas (REIS), 85, pp. 97-129. https://doi. org/10.2307/40184101

22. Morán, María Luz y Benedicto, Jorge. (1995). La cultura política de los españoles: un ensayo de reinterpretación. Madrid: Centro de Investigaciones Sociológicas.

23. Piña-Osorio, Juan Manuel. (2008). La cultura política en los estudiantes de la Universidad Autónoma Chapingo. Agricultura, Sociedad y Desarrollo, 5 (1), pp. 93-113.

24. Taguenca Belmonte, Juan Antonio. (2013). La cultura política de los jóvenes universitarios en Hidalgo: un estudio sobre sus opiniones y actitudes con respecto a la democracia. Tla-Melaua: Revista de Ciencias Sociales, 6 (33), pp. 6-25. https://doi. org/10.32399/rtla.6.33.33 
Representaciones sobre la democracia, las instituciones y los actores gubernamentales...

25. Vélez, Eduardo; Santamaría, Ricardo y Silva, Gabriel. (1984). La juventud universitaria y el sistema político: ¿caminos divergentes? En: Latorre Rueda, Mario (ed.). Juventud y política en Colombia. Bogotá, D. C.: Fescol, Instituto Ser de Investigación.

26. Zapata, Mónica y Muñoz, Henry. (2013). Cultura política y valores políticos en contextos universitarios de carácter público y privado de Medellín. (Tesis inédita de pregrado). Universidad de Antioquia, Medellín. 